\title{
MICROECONOMETRIC MODELING OF RENT AS A MEASURE OF NATURAL RESOURCE SCARCITY: REGULARITY AND TECHNICAL CHANGE, SCALE, AND FUNCTIONAL FORM SENSITIVITY UNDER PARTIAL STATIC EQUILIBRIUM'
}

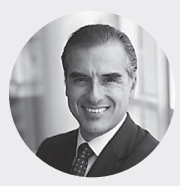

\author{
ANDRÉS A. ESCALANTE \\ - Facultad de Negocios \\ Universidad Peruana de Ciencias Aplicadas
}

RESUMEN

Esta investigación tiene dos objetivos. El primero consiste en evaluar la sensibilidad estadística de la renta, como medida de escasez de un recurso natural, hacia las especificaciones econométricas de la función de costo variable, de la que puede derivarse. Ello con el fin de examinar si los supuestos para formular el modelo econométrico generan diferencias estadísticamente relevantes en la renta estimada. El segundo objetivo de la investigación consiste en determinar si las decisiones ejecutivas de investigación y la consistencia teórica del modelo afectan el contenido informacional de la renta, como medida de escasez de dicho recurso. La muestra consiste en series de tiempo de 1953 a 1985 de la industria de asbestos en Canadá. Esta investigación evidencia que estas decisiones sí generan diferencias pero no como para afectar la consistencia informacional de la renta. En particular, los resultados empíricos revelan una sensibilidad de la renta ante los supuestos sobre la escala de operaciones y el cambio tecnológico y sobre todo ante las propiedades de regularidad. La consistencia informacional de la renta resulta de su movimiento unidireccional a través de las variaciones en el modelo original y que en esta oportunidad estaría sugiriendo una mayor escasez a lo largo de la muestra. Estos resultados respaldan el enfoque microeconómico de medir la escasez de los recursos naturales con métodos econométricos clásicos.

Palabras Clave: Microeconometría, Modelado de superficie respuesta, Regularidad teórica, Cambio técnico, Escala, Forma funcional, Función de costo, Equilibrio estático parcial

\section{ABSTRACT}

This paper has two objectives. The first consists of evaluating the statistical sensitivity of rent, as a measure of natural resource scarcity, to econometric specifications of the variable cost function, from which it can be derived, in order to assess whether assumptions on model characteristics translate into statistically different rent estimates. The second objective of this study consists of determining whether research decisions and theoretical consistency affect information content of a resource scarcity measure based on rent. Canadian asbestos industry 1953-1985 time-series data are used. This paper shows that research decisions do make a difference but not to the extent of affecting the information consistency of rent as a measure of resource scarcity. In particular, it finds rent sensitive to scale and technical change assumptions, as well as to regularity properties. Informational consistency of rent results from its unidirectional movement across model specifications, and which, in this case, it seems to be suggesting increasing scarcity over the sample period. These findings support the microeconomic approach to measuring resource adequacy based on classical econometrics.

Key Words: Microeconometrics, Response surface modelling, Theoretical regularity, Technical change, Scale, Functional form, Cost function, Partial static equilibrum

\section{INTRODUCTION}

The literature on measuring natural resource scarcity since the 1960 s has been largely devoted to assessing whether resources are becoming scarce and present limits to growth. ${ }^{2}$ This literature has been largely empirical and has involved looking at physical and economic measures of scarcity. ${ }^{3} \mathrm{~A}$ literature review clearly shows increasing use of economic theory and 
econometrics in measuring scarcity. ${ }^{4}$ A great deal has been accomplished. We have a better understanding of the relationship between economic activity and resource constraints as a result of using economic foundations for the measurement of scarcity. But it is also evident that there remain important theoretical and empirical issues concerning the measurement of scarcity which hitherto have not been addressed in comprehensive fashion. The purpose of this study is to conduct a comprehensive analysis of some of the theoretical and econometric issues underlying the use of economic rent as a measure of resource scarcity in applied economics.

Rent is an appropriate measure of scarcity if interest lies on the adequacy of the un-extracted resource (i.e., reserves), free of labor or any other factor of production. It is the shadow price for the marginal unit of resource in situ. Reserves are a quasi-fixed input for which there is no market price or market rental rate as a result of the vertically integrated production structure of the mining industry or any other nonrenewable resource extractive industry. Reserves thus contrast labor or any other input for which a market valuation exists. Rent, fortunately, can be determined mathematically using Hotelling's lemma on the variable cost function.

To set the stage for this study, therefore, consider the relationship between the econometric determination of rent and the variable cost function. For estimation, the variable cost function must be specified econometrically. Specification involves research decisions that define the characteristics of the model both before (ex ante) and after estimation (ex post). Ex ante characteristics entail testable and maintained hypotheses. Testable hypotheses relate to functional form, scale, and technical change. Maintained hypotheses relate to the regularity properties of symmetry and homogeneity of the variable cost function. These characteristics summarize our a priori perception of the technology for extracting and processing in mining. Ex post characteristics involve diagnostics on the regularity properties of monotonicity, concavity, and convexity of said function. It is, therefore, important to examine whether alternative assumptions on model characteristics translate into different rent estimates; and, if so, whether research decisions affect the information content of rent as a measure of scarcity.

Evaluating the role of research decisions on the econometric determination of rent does not mean questioning whether research decisions matter. Research decisions do matter because they detail the specification of the variable cost function from which rent can be derived. But is rent sensitive to model? Does rent convey the same information on scarcity under different sets of assumptions on model characteristics? How robust are rent estimates to research decisions? This analysis also addresses whether research decisions affect the information content of rent as a measure of scarcity. These questions expose broad issues that are important in empirical resource economics for their potential methodological implications, and therefore provide, to a large extent, the motivation for this work.

Theoretical consistency is a case in point. The variable cost function satisfies the regularity properties of symmetry, nonnegativity, monotonicity, first-degree homogeneity, concavity, and convexity. Any specification of the variable cost function must satisfy these properties empirically if the theory of restricted cost minimization is to serve as organizing principle. Nonnegativity is satisfied because the domain and the range of the variable cost function are positive. Symmetry and first-degree homogeneity are imposed a priori as maintained hypotheses. These latter two properties involve linear parametric restrictions whose implementation is straightforward and required for a minimally consistent model. On the other hand, monotonicity, concavity, and convexity involve parametric restrictions based on algebraic inequalities for which there is no method to reparametrize the model such that these properties are satisfied a priori within the confines of classical econometrics. Whether these properties are satisfied by the specification of the variable cost function is, therefore, verified a posteriori. But does it make a difference whether the specification of the variable cost function is consistent with theory to the extent that these differences affect the information content of rent as a measure of scarcity? And does this indicate that in future research more effort should be placed in imposing theory consistency as prior information?

We might pause to question the object of determining whether the rent is sensitive to the characteristics of the model from which it is derived. Why is it important? It is important because alternative specifications imply research decisions for the characteristics of the model that are largely subjectively determined. If rent is sensitive to the characteristics of the model, then we stand before a large number of specifications from which to choose. Here, choice presents an apparent dilemma. In classical econometrics there is no rule for choosing one specification over another, apart from simple criteria often used for regressor selection and for assessing model adequacy (e.g., $t$ and $F$ tests, $\mathrm{R}^{2}$, Akaike's information criterion). The choice of one specification over another is largely based on subjective criteria. Model selection thus becomes a difficult problem for which no single solution exists. It is thus very important to examine, given this dilemma, if rent estimates resulting from competing sets of research decisions are informationally consistent. In other words, would rent convey the same information about scarcity before the possibility of being statistically different across models? If choice brings forth a problem of selection, that is, it is correct to wonder whether it also poses an interpretation problem.

Economists have not paid proper attention to the problems of selection and interpretation inherent to specification choice in their effort to measure resource scarcity with more theory. These problems, doubtlessly, are important and worthy of analysis. This study, as a step in this direction, therefore, has two objectives. The first consists of evaluating the sensitivity of rent as a measure of resource scarcity to the empirical specifications of the variable cost function in order to assess whether alternative sets of assumptions on model characteristics translate into statistically different rent estimates. The second objective consists of evaluating whether research decisions and theoretical consistency affect the information content of rent as a measure of scarcity.

Pursuit of these objectives requires a methodology that exploits what Berndt (1991) referred to as the nexus between theory and practice. The theory of restricted cost minimization serves to this effect as organizing principle for the study. The variable cost function is the theoretical model. It is used to describe the production technology for extracting and processing a mineral. Output 
is fixed and assumed to have been determined through a technologically feasible combination of labor, energy, and materials, as variable inputs; and capital and reserves as quasi-fixed inputs. Technology is thus assumed to be in short-run equilibrium.

The transcendental logarithmic (translog) functional form is used to specify the variable cost function into six different models. In terms of functional form, five of these six models are specified to be parametrically linear. As far as scale, each model is assumed to be either homothetic or non-homothetic as well as homogeneous. The assumptions on technical change include form and a corresponding adjustment mechanism. As far as form, exogenous and either factor-biased or Hicks-neutral technical change is assumed for each but one of the linear models. These models, moreover, are subject to a static adjustment mechanism for technical change. The nonlinear model employs a dynamic adjustment mechanism for technical change that is exogenous as well as endogenous, in addition to being factor-biased.

These models are estimated using seemingly unrelated regression (SUR) methods and nonlinear maximum likelihood (NLML). Parameter estimates for the linear models, in particular, are obtained using an iterative version of SUR in the spirit of Zellner (1962). NLML is used to obtained parameter estimates for the nonlinear model. A grid search and nonlinear SUR are used to obtain the initial conditions for the NLML estimates, derived in an iterative environment provided by the DavidsonFletcher-Powell algorithm. The estimation of these models varies in complexity due to parametric restrictions implied by the characteristics adopted for each model. The data consist of time series for the Canadian asbestos industry for the 1953-1985 period. Estimation of these models allows not only for the possibility to learn about the relationship between rent and executive research decisions, but also, and quite importantly, to determine whether the empirical results lend support to a microeconomic approach to measuring resource scarcity using classical econometrics.

Rent is derived from these models upon estimation as the negative of the partial derivative of the translog variable cost function with respect to reserves. A rent index is obtained from each model and used in aggregate form in a response surface model to evaluate its sensitivity to the characteristics of translog variable cost function. The evaluation consists of two parts. The first involves examining whether these indexes are statistically different from each other. It provides for the possibility to ascertain whether research decisions make a difference in determining the value of rent econometrically. This part itself involves two steps. The first determines whether the indexes share the same statistical mean. The second step establishes whether the respective means of these indexes are statistically different from each other. The second part of the sensitivity analysis involves fitting a response surface to rent in order to evaluate statistically its relationship to functional form, scale characteristics, and technical change, as well as to the regularity diagnostics of the model from which it is derived.

The response surface furnishes a relatively simple yet comprehensive mechanism for assessing whether the characteristics of each model have any statistical effect on its corresponding rent index and thereby appraising the robustness of our measures of scarcity to research decisions.

Expanding on this theme, the sample is used to evaluate whether research decisions and theoretical consistency affect the information content of rent as a measure of scarcity. These indexes are said to be informationally consistent if they move in the same direction and convey the same information. If research decisions make a difference, then we sit before six models from which to choose. As it was mentioned earlier, this is more a problem than a blessing because apart from mechanical applications of measures involving goodness of fit, there is no rule in classical econometrics for choosing one model over another. Knowing that these indexes move in the same direction would, therefore, minimize the selection problem intrinsic to specification choice. Whether they move together or not is addressed using a correlation matrix in addition to the response surface. The direction of movement is addressed by estimating the trend of the indexes as a sample and in individual form. Given our state of knowledge and the quality of the data, this is a conservative interpretation of the importance of the research findings presented in this study

\section{THEORETICAL FOUNDATIONS}

In the theory of restricted cost minimization, there is a difference between short and long-run production possibilities inasmuch as it regards production technology as a transformative scheme under temporary equilibrium. Temporary equilibrium exists whenever the demand for a quasi-fixed factor of production $(z)$ is inconsistent with long-run cost-minimizing behavior. Under temporary equilibrium, accordingly, there can only be a short-run interpretation of producer behavior. Static equilibrium exists, in contrast, when the demand for $\boldsymbol{z}$ is consistent with long-run cost-minimizing behavior. It actually provides for both a short and a long-run interpretation of producer behavior inasmuch as the envelope theorem serves as a link between both equilibria

Temporary and static equilibria can be alternatively described in terms of the relationship between the firm's internal valuation of $z$ and its external or market valuation. The internal valuation of $\boldsymbol{z}$ is the shadow cost $(\mu)$, and the market valuation refers to its rent or rental price $(p)$. Temporary equilibrium exists whenever $\mu$ differs from $p$. The condition $p=\mu$ can be taken, therefore, as one way to represent the envelope condition for static equilibrium in $z$ as it provides for the possibility to solve for optimal demand $\left(z^{*}\right)$.

Technology under temporary equilibrium is described in the dual space with the variable cost function. ${ }^{.}$The variable cost function is defined as

$$
c v(\mathbf{w}, q \mid \mathbf{z}) \equiv \operatorname{argmin}_{\mathbf{x}}\left[\boldsymbol{w}^{\prime} \boldsymbol{x}: f(\boldsymbol{x} \mid \mathbf{z}) \geq q ; q \geq 0, \boldsymbol{x} \geq \mathbf{0}_{n}, \mathbf{z} \geq \mathbf{0}_{m}\right]
$$


where $w$ is an $n$-dimensional vector of variable factor prices; $q$ is maximum output rate per unit of time; $z$ is an $m$-order vector of quasi-fixed inputs; $x$ is an $n$-order vector of variable inputs; and $f: R^{(n+m)} \rightarrow R$ is a well-behaved production function that defines an equivalent relationship between $q, x$ and $z$ in the primal space. ${ }^{6}$ The variable cost function specifies the minimum variable $\operatorname{cost}^{7}$ of producing $q$ subject to $w, z$ and $f(f(\cdot)$. It satisfies the regularity properties of symmetry, non-negativity, monotonicity, first-degree homogeneity, and concavity in $w$; monotonicity and non-negativity in $q$; and symmetry, non-negativity, nonincreasingness, and convexity in $z$. It specifies a mathematical optimization problem of restricted nature: minimize the variable cost of producing q subject to $w, z$, and $f(\cdot)$.

Technology under static equilibrium is described in the dual space with the total or long-run cost function. This function is itself derived from the short-run cost function, defined as.

$$
c^{S R}(\boldsymbol{w}, q \mid \mathbf{z}) \equiv c v(\boldsymbol{w}, q \mid \mathbf{z})+\boldsymbol{p}^{\prime} \mathbf{z}
$$

where $p$ is an $m$-vector of typically observed quasi-fixed factor rental prices. The long-run cost function is, accordingly, defined as

$$
c\left(\mathbf{w}, q \mid \mathbf{z}^{*}\right) \equiv \operatorname{argmin}_{\mathrm{z}}\left[c v(\boldsymbol{w}, q \mid \mathbf{z})+\boldsymbol{p}^{\prime} \mathbf{z}\right],
$$

where $z^{*}$ is consistent with the envelope theorem under static equilibrium. The long-run cost function satisfies the regularity properties of $c v(\cdot)$ because it is expressed as the envelope of $c^{S R}(\cdot)$. Note that, unlike $c^{S R}(\cdot), c(\cdot)$ does not depend on $z$ and implies, mathematically, an optimization problem consisting of minimizing $c v(\cdot)$ and solving for $z^{*}$.

The long-run cost function is less than $c^{S R}(\cdot)$ except when $z=z^{*}$, point at which both functions become equal according to the envelope theorem. By Shephard's lemma, points common to both functions satisfy

$$
\nabla_{\mathbf{z}} c v(\mathbf{w}, q \mid \mathbf{z})+\boldsymbol{p}=\mathbf{0}
$$

Equation (4) is a general system of $m$ nonlinear equations that represent first-order conditions for static equilibrium and an interior solution. In principle, $z^{*}$ can be found using equation (4), and long-run cost can be determined by substituting $z^{*}$ into equation (2), allowing for the following expression:

$$
c\left(\boldsymbol{w}, q \mid \mathbf{z}^{*}(\boldsymbol{w}, q, \boldsymbol{p})\right) \equiv c v\left[\boldsymbol{w}, q \mid \mathbf{z}^{*}(\cdot)\right]+\boldsymbol{p}^{\prime} \mathbf{z}^{*}(\cdot),
$$

Equation (4) provides for the possibility to characterize temporary and static equilibria in terms of the $m$-order vector of quasi-fixed factor shadow prices. The shadow price of $z$ is obtained as $-\frac{\partial c v(\cdot)}{\partial z}$ by invoking Hotelling's lemma. ${ }^{8}$ The shadow cost is negative because $c v(\cdot)$ is non-increasing in $z$. Quasi-fixed factor $z$ has a positive but diminishing marginal product: its value to the firm decreases across equilibria. The absolute value of $\mu$, that is, falls as $z$ is adjusted to $z^{*}$. The envelope condition for $z$ clearly shows that $\mu$ depends on $w, z$, and the technology. Temporary equilibrium exists, therefore, when $-\mu>p$ or $-\mu$ $<p$, subject to $z$. Static equilibrium exists, on the other hand, when $z=z^{*}$ or, equivalently, when $-\mu=p$. That is, the producer acquires $z$ up to the point at which the decrease in variable cost (i.e., $\mu$ ), is exactly balanced by the marginal cost increment (i.e., (p). Equilibrium is obtained by adjusting $z$ and by implicitly adjusting $\mu$.

\section{ECONOMETRIC MODELING}

The variable cost function is specified into six models to account for alternative forms of functional specification, technical change and scale under temporary equilibrium. Each 


\section{Table 1.- Econometric models and ex ante characteristics}

\begin{tabular}{|c|c|c|c|c|c|}
\hline \multirow{2}{*}{ Model } & \multirow{2}{*}{$\begin{array}{l}\text { Functional } \\
\text { Form }\end{array}$} & \multicolumn{2}{|c|}{ Technical Change } & \multirow{2}{*}{ Scale } & \multirow{2}{*}{$\begin{array}{c}\text { Estimation } \\
\text { Method }\end{array}$} \\
\hline & & Source and Form & $\begin{array}{l}\text { Adjustment } \\
\text { Mechanism }\end{array}$ & & \\
\hline 1 & Nonlinear & $\begin{array}{l}\text { Endogenous- } \\
\text { exogenous and } \\
\text { factor-biased }\end{array}$ & Dynamic & $\begin{array}{l}\text { Non-homothetic/ } \\
\text { nonhomogeneous }\end{array}$ & $\begin{array}{c}\text { Nonlinear } \\
\operatorname{MLE}^{\mathrm{a}}\left(\mathrm{SUR}^{\mathrm{b}}\right)\end{array}$ \\
\hline 2 & Linear & $\begin{array}{l}\text { Exogenous and } \\
\text { factor-biased }\end{array}$ & Static & $\begin{array}{l}\text { Non-homothetic/ } \\
\text { nonhomogeneous }\end{array}$ & $\mathrm{IZEF}^{\mathrm{c}}$ \\
\hline 3 & Linear & $\begin{array}{c}\text { Exogenous and } \\
\text { Hicks-neutral }\end{array}$ & Static & $\begin{array}{c}\text { Homothetic/ } \\
\text { Nonhomogeneous }\end{array}$ & IZEF \\
\hline 4 & Linear & $\begin{array}{c}\text { Exogenous and } \\
\text { Hicks-neutral }\end{array}$ & Static & $\begin{array}{l}\text { Non-homothetic/ } \\
\text { nonhomogeneous }\end{array}$ & IZEF \\
\hline 5 & Linear & $\begin{array}{c}\text { Exogenous and } \\
\text { Hicks-neutral }\end{array}$ & Static & $\begin{array}{c}\text { Homothetic/ } \\
\text { nonhomogeneous }\end{array}$ & IZEF \\
\hline 6 & Linear & $\ldots$ & $\ldots$ & $\begin{array}{l}\text { Non-homothetic/ } \\
\text { nonhomogeneous }\end{array}$ & IZEF \\
\hline
\end{tabular}

a/ ... stands for not applicable.

b/ MLE stands for maximum likelihood estimation and SUR for seemingly unrelated regression. c/ IZEF stands for iterative Zellner efficient estimation.

model thus displays an alternative set of both mathematical and economic information by which it is possible to identify a theoretically feasible production environment. The models are estimated using SUR methods and NLML. Table 1 details how $c v(\cdot)$ is specified and estimated at each case.

Estimation of these models can be complex and varies across models largely as a result of the parametric restrictions implied by the ex ante characteristics adopted for each model. A case in point involves functional form. In the present context, a nonlinear functional form is estimated with a nonlinear SUR equation system, whose nature and level of complexity are considerably different and higher, respectively, than what we would typically encounter in estimating a linear SUR system of equations, proper of a linear functional form. Parametric restrictions, derived from imposing factor symmetry and price homogeneity a priori upon $c v(\cdot)$, are also responsible for why the estimation of these models can vary in nature. These restrictions, however, do not increase the level of complexity of such exercise. In fact, it is quite the opposite, for their application actually facilitates the estimation process. Regularity diagnostics, which comprise the ex post characteristics of the technology in each model, do not affect its estimation either as they are obtained a posteriori.

\subsection{Variable Cost Function Specification}

The variable cost function is specified as a translog functional form, ${ }^{9}$ expressible generically for all six models of Table 1 as.

$$
\begin{gathered}
\operatorname{lncv}(w, q \mid z ; t)=\alpha_{0}+\sum_{i=1}^{n} \alpha_{i} \ln w_{i}+\frac{1}{2} \sum_{i=1}^{n} \sum_{j=1}^{n} \beta_{i j} \ln w_{i} \ln w_{j}+\sum_{r=1}^{m} \alpha_{r} \ln z_{r}+\frac{1}{2} \sum_{r=1}^{m} \sum_{g=1}^{m} \beta_{r g} \ln z_{i} \ln z_{g}+\frac{1}{2} \sum_{i=1}^{n} \sum_{r=1}^{m} \beta_{i r} \ln w_{i} \ln z_{r}+ \\
\alpha_{q} \ln q+\frac{1}{2} \beta_{q q}(\ln q)^{2}+\sum_{i=1}^{n} \beta_{i q} \ln w_{i} \ln q+\sum_{r=1}^{m} \beta_{r q} \ln z_{r} \ln q+\tau_{0}(\cdot)+\sum_{i=1}^{n} \tau_{i}(\cdot) \ln w_{i}+\sum_{r=1}^{m} \tau_{r}(\cdot) \ln z_{r}
\end{gathered}
$$

where $\operatorname{Incv}(\cdot)$ is the natural logarithm of the variable cost function; $\alpha$ and $\beta$ are parametric constants; Inw, Inz and Inq are the natural logarithms of factor price $\boldsymbol{w}$, quasi-factor $\boldsymbol{z}$, and output $q$, respectively; $\tau_{0}(\cdot), \tau_{i}(\cdot)$, and $\tau_{r}(\cdot)$, are three technological indexes to account for different forms of technical change; and $t$ stands for time. Equation (6) is a second-order numerical approximation in logarithms to $c v(\cdot)$, that permits the description of economically relevant aspects of producer behavior through its first and second-order partial derivatives (i.e., $\alpha$ and $\beta$ ), without imposing a priori constraints across effects. In presence of $n$ and $m$ variable and quasi-fixed inputs, and one output, the translog specification displays $n+m+1$ different variables and $\frac{(k+1)(k+2)}{2}$ separate economic effects, where $k=n+m+1$ 


\subsection{Technical Change}

Term $t$ is included as an argument to $\operatorname{Incv}(\cdot)$ to account for technical change in the spirit of Binswanger (1974). How $t$ relates to $\operatorname{Incv}(\cdot)$ depends on the characteristics of $\tau_{0}(\cdot), \tau_{i}(\cdot)$, and $\tau_{r}(\cdot)$. These technological indexes are attached to an otherwise conventional translog specification for $c v(\cdot)$ to gauge the different forms in which technical change can manifest itself. The presence of each index and their functional arguments depend on the assumptions on technical change entertained for each model. These assumptions involve the form technical change can take and its causes. Neutral and biased representations of disembodied technical change are considered as far as form, and both exogenous and endogenous (i.e., induced) technical change as far as causation..$^{10}$

Neutral technical change is interpreted according to Hicks (1963). ${ }^{11}$ Hicks-neutral change represents a parallel translation of $c v(\cdot)$ across space; a shift of $c v(\cdot)$ that is independent of the cost share of any production factor $(x)$, the shadow price of $\boldsymbol{z}$, and scale. It is modeled here with the natural logarithm of $\tau_{0}(\cdot)$, strictly for purposes of mathematical conveniences. This index or function is a shifter and vanishes upon the partial differentiation of $\operatorname{Incv}(\cdot)$ with respect to $w, z$, and $q$. It is, in addition, the only part of $\operatorname{Incv}(\cdot)$ assumed to capture all neutral change--a fact which implies, in terms of equation $(6), \frac{\partial \operatorname{In} c v(\cdot)}{\partial \ln \tau_{0}(\cdot)}=1$ Biased technical change, in contrast, represents a modification of the gradients in both $w$ and $z$. Technical bias affecting these gradients are modeled with $\tau_{i}(\cdot)$ for $\boldsymbol{w}$ and $\tau_{r}(\cdot)$ for $\boldsymbol{z}$.

What drives $\ln \tau_{0}(\cdot), \tau_{i}(\cdot)$ and $\tau_{z}(\cdot)$ depends on whether technical change is exogenous or endogenous. Only Model 1 accounts simultaneously for both sources of causation--very much in the spirit of Lasserre and Ouellette (1991). ${ }^{12}$ It accounts for endogenous change by interpreting technical change as a discrete phenomenon largely induced by economic considerations, and thereby, driven by variables that are best summarized by the date. It accounts for exogenous change by relating $\ln \tau_{0}(\cdot)$, $\tau_{i}(\cdot)$ and $\tau_{z}(\cdot)$ to an exogenous element, assumed to evolve with time, and represented by $t$.

Considering technical change as both an endogenous and an exogenous phenomenon in this way provides for the possibility to specify, functionally, $\ln \tau_{0}, \tau_{i}$ and $\tau_{r}$ as follows, respectively: $\ln \tau_{0}\left(\pi_{t-\infty}, \ldots, \pi_{t-1} ; t\right), \tau_{i}\left(\boldsymbol{w}_{t-\infty}, \ldots, \boldsymbol{w}_{t-1}, q_{t-\infty}, \ldots, q_{t-1}, \mathbf{z}_{t-\infty}, \ldots, \mathbf{z}_{t-1} ; t\right)$ , and $\tau_{r}\left(\boldsymbol{w}_{t-\infty}, \ldots, \boldsymbol{w}_{t-1}, q_{t-\infty}, \ldots, q_{t-1}, \mathbf{z}_{t-\infty}, \ldots, \mathbf{z}_{t-1} ; t\right)$, where $\pi$ represents the ratio of total revenue to variable cost. Prices drive $\tau_{i}$ and $\tau_{r}$ in the tradition of the induced-bias hypothesis because through technical change, it is possible for the producer to adjust, for example, to a rise in price by substituting out the relatively expensive input. Quasi-fixed factor levels also drive $\tau_{i}$ and $\tau_{r}$ because larger quantities of these inputs suggest increased availability of stock, which should induce the producer to rely increasingly on them. Finally, in the spirit of Galbraithian and Schumpeterian theories, in which size is a determinant to technical change, and of the "learning-by-doing" hypothesis, in which cumulative output is of key importance, past output levels are also relevant: they may affect biases, as opportunities for changing factor proportions can differ according to scale. The ratio $\pi$ drives $\ln \tau_{0}$ in face of increasing evidence in the literature of the effect that future profit opportunities, arising from market power, for example, have upon technical change. Its inclusion as an argument, moreover, is consistent with Schumpeterian and other rather recent theories on technical change. Model 1 considers lagged as opposed to current levels because it assumes technical change as a phenomenon that requires time to materialize--a fact which should imply a paused and dynamic adjustment mechanism of the technology to neutral and biased changes.

Model 1, in this context, assumes a geometric distributed lag form for the functional specification $\tau_{i}, \tau_{r}$ and $\ln \tau_{0}$. The specification is reduced using the Koyck (1953) transformation to functions involving an adjustment constant $(\lambda)$ for purposes of estimation in each instance. ${ }^{13}$ Thus,

$$
\begin{gathered}
\tau_{i}(\cdot)=\sum_{j=1}^{n} \frac{v_{i j}}{1-\lambda L} \ln w_{j_{t-1}}+\sum_{r=1}^{m} \frac{v_{i r}}{1-\lambda L} \ln z_{r_{t-1}}+\frac{v_{i q}}{1-\lambda L} \ln q_{t-1}+\alpha_{i t} t, \\
\tau_{r}(\cdot)=\sum_{j=1}^{n} \frac{v_{r j}}{1-\lambda L} \ln w_{j_{t-1}}+\sum_{g=1}^{m} \frac{v_{r g}}{1-\lambda L} \ln z_{r_{t-1}}+\frac{v_{r q}}{1-\lambda L} \ln q_{t-1}+\alpha_{r t} t, \\
\ln \tau_{0}(\cdot)=\frac{v_{\pi}}{1-\lambda L} \ln \pi_{t-1}+\frac{1}{2} \beta_{t t} t^{2},
\end{gathered}
$$

where $v, \alpha$, and $\beta$ are constant parameters, $L$ is the lag operator and $i=1, \ldots, n$, and $r=1, \ldots, m$. The specification of $\ln \tau_{0}(\cdot)$ includes the accelerator term $t^{2}$ to allow for changes in the time trend.

The simultaneous consideration of technical change as an endogenous as well as an exogenous phenomenon rests on both not being mutually exclusive: even though exogenous technical opportunities exercise a significant role in innovation, technical change is to an extent an endogenous process similar in nature to investment. ${ }^{14}$ It is common in practice, however, to account for technical change as an exogenous phenomenon exclusively. The reason for this is simple: exogenous change is assumed to take place in a nonsystematic form and the corresponding adjustment mechanism only requires, as a result, a static interpretation--which is easier than its dynamic similar as far as handling. Models 2 through 5 take this fact into account and relax the concern with endogenous change. These models, that is, only entertain technical change as an exogenous phenomenon. The adjustment mechanism of the technology to exogenous change is therefore assumed to be static and the three technological indexes become exclusive functions of $t$; that is, $\ln \tau_{0}(t), \tau_{i}(t)$, and $\tau_{r}(t)$. For Models 2 through 5 , therefore, 


$$
\begin{gathered}
\tau_{i}(\cdot)=\sum_{i=1}^{n} \beta_{i t} t, \\
\tau_{r}(\cdot)=\sum_{r=1}^{m} \beta_{r t} t, \\
\ln \tau_{0}(\cdot)=\alpha_{t} t+\frac{1}{2} \beta_{t t} t^{2},
\end{gathered}
$$

\subsection{Scale}

Scale imposes structure on the variable cost function. Technology can be homothetic or non-homothetic as far as scale. In the literature it has been common practice to assume a non-homothetic variable cost function to describe technology. This trend is followed to a large extent in this research. Models 1, 2, 4, and 6 assume a non-homothetic technology in evaluating the sensitivity of rent to assumptions on scale, while models 3 and 5 entertain a homothetic technology. This is possible because flexible functional forms do not constrain the empirical specification of $c v(\cdot)$ to be either homothetic or non-homothetic a priori; we can, in principle, contemplate each possibility as a maintained hypothesis or statistically test for their presence..$^{15}$

Homotheticity implies that $c v(\cdot)=a(\boldsymbol{w} \mid \mathbf{z}) \times j(q)$, where $a(\cdot)$ is a well-behaved function in $w$ and $z$, and $j(\cdot)$ is a well-behaved function in $q{ }^{16}$ It implies a relationship between $c v, w$ and $q$ that is multiplicatively separable, and, as a result, cost-minimizing demand ratios that are independent of output. Homotheticity implies that equation (6) can thus be expressed as

$$
\begin{gathered}
c v(\cdot)=\exp \left[\alpha_{0}+\sum_{i=1}^{n} \alpha_{i} l n w_{i}+\frac{1}{2} \sum_{i=1}^{n} \sum_{j=1}^{n} \beta_{i j} l n w_{i} l n w_{j} \sum_{r=1}^{m} \alpha_{r} l n z_{r}+\frac{1}{2} \sum_{r=1}^{m} \sum_{g=1}^{m} \beta_{r g} \ln z_{r} l n z_{g}+\frac{1}{2} \sum_{i=1}^{n} \sum_{j=1}^{m} \beta_{i j} l n w_{i} l n z_{r}+\tau_{0}(\cdot)+\sum_{i=1}^{n} \tau_{i}(\cdot) l n w_{i}+\sum_{r=1}^{m} \tau_{r}(\cdot) l n z_{r}\right] \\
\times \exp \left[\alpha_{q} \ln q+\frac{1}{2} \beta_{q q}(I n q)^{2}+\sum_{i=1}^{n} \beta_{i q} l n w_{i} l n q+\sum_{r=1}^{m} \beta_{r q} \ln z_{r} l n q\right]
\end{gathered}
$$

Models 2 and 4 account for homotheticity by imposing the parametric restrictions $\beta_{i q}=\beta_{r q}=0$ on equation (6) a priori.

Technology can also be homogeneous or nonhomogeneous as far as scale. A homogeneous function is a special case of homothetic function. ${ }^{17}$ Any homogeneous function is homothetic though the converse need not hold. The variable cost function, accordingly, can be homogeneous if it has been first determined to be homothetic. If $f(\cdot)$ is homogeneous of degree $r$ in $\boldsymbol{x}$, it can be shown that $c v(\cdot)$ is be homogeneous of degree $r$ in $q$. Whether technology is homogeneous of degree $r$ in $q$ in the primal space or in $q$ in dual space can also be tested statistically or assumed as a maintained hypothesis because flexible functional forms do not restrict its empirical specification to be one or the other a priori either. Homogeneity implies $c v(\cdot)=a(\boldsymbol{w} \mid \boldsymbol{z}) \times q^{1 / r}$, where variable cost, factor price, and output relate to each other in a multiplicative separable manner as well. ${ }^{18}$ Homogeneity implies further parametric restrictions on equation (6). In addition to $\beta_{i q}=\beta_{r q}=0$, restriction $\beta_{q q}=0$ , by which the degree of homogeneity becomes $1 / q$, is required a priori. All six models of Table 1 , however, only entertain a nonhomogeneous technology for simplicity.

\subsection{Recapitulation}

Having discussed the different assumptions on technical change, scale, and equilibrium entertained for the models of Table 1 , a pause is in order to show, for purposes of organization and clarity, how these assumptions affect the translog variable cost function-i.e., equation 6-in each case. Model 1 is highly demanding technically. However, its comprehensiveness permits us to derive from its structure models 2 through 6 by just restricting to zero those parameters that are incongruent with the assumptions pertaining to each model.

Model 1 assumes endogenous, exogenous, and factor-biased technical change. This theoretically feasible phenomenon is modeled according to Lasserre and Ouellette, in terms of which into an otherwise convention translog variable cost function, a dynamic adjustment mechanism to technical change is incorporated. As for scale, moreover, the technology is assured to be non-homothetic and non-homogeneous. Model 1 is thus obtained by substituting $\tau_{i}(\cdot), \tau_{r}(\cdot)$, and $\tau_{0}(\cdot)$ in equation (6), with the right-hand expressions of equations (7), (8), and (9), respectively; that is,

$$
\begin{aligned}
& \operatorname{lncv}(w, q \mid z ; t)=\alpha_{0}+\sum_{i=1}^{n} \alpha_{i} \ln w_{i}+\frac{1}{2} \sum_{i=1}^{n} \sum_{j=1}^{n} \beta_{i j} \ln w_{i} \ln w_{j}+\sum_{r=1}^{m} \alpha_{r} \ln z_{r}+\frac{1}{2} \sum_{r=1}^{m} \sum_{g=1}^{m} \beta_{r g} \ln z_{i} \ln z_{g}+\frac{1}{2} \sum_{i=1}^{n} \sum_{r=1}^{m} \beta_{i r} \ln w_{i} \ln z_{r} \\
&+\alpha_{q} \ln q+\frac{1}{2} \beta_{q q}(\operatorname{lnq})^{2}+\sum_{i=1}^{n} \beta_{i q} \ln w_{i} \ln q+\sum_{r=1}^{m} \beta_{r q} \ln z_{r} \ln q+\sum_{j=1}^{n} \frac{v_{i j}}{1-\lambda L} \ln w_{j_{t-1}}+\sum_{r=1}^{m} \frac{v_{i r}}{1-\lambda L} \ln z_{r_{t-1}}+\frac{v_{i q}}{1-\lambda L} \ln q_{t-1}+\alpha_{i t} t \\
&+\sum_{j=1}^{n} \frac{v_{r j}}{1-\lambda L} \ln w_{j_{t-1}}+\sum_{g=1}^{m} \frac{v_{r g}}{1-\lambda L} \ln z_{r_{t-1}}+\frac{v_{r q}}{1-\lambda L} \ln q_{t-1}+\alpha_{r t} t+\frac{v_{\pi}}{1-\lambda L} \ln \pi_{t-1}+\frac{1}{2} \beta_{t t} t^{2}
\end{aligned}
$$


Model 2 assumes a non-homothetic, non-homogeneous technology, subject to exogenous and factor-biased technical change. To capture these assumptions, the right-hand side expression of equations (10), (11), and (12), are used instead in specifying $\tau_{i}(\cdot)$, $\tau_{r}(\cdot)$, and $\tau_{0}(\cdot)$ in equation (6). In model 3 , the technology is assumed to be homothetic, and non-homogeneous, and subject to exogenous and factor-biased technical change. Equation (6) turns into model 3 by restricting the values of $\beta_{i q}$ and $\beta_{r q}$ to zero a priori to model homotheticity. Model 4 assumes a technology subject to Hicks-neutral technical change, itself modeled by restricting $\tau_{i}(\cdot)$ and $\tau_{r}(\cdot)$ to zero. Model 5 is unique, inasmuch as it assumes a technology under exogenous and Hicks-neutral technical change, that is both homothetic and non-homogeneous. These assumptions make of model 5 the most restrictive model of Table 1. Model 6 is equally unique, for it assumes no technical change. This rather extreme assumption is nevertheless useful if one wishes to know whether or not it is justifiable to account for technical change at all in estimating natural resource rent. The absence of technical change is obtained by restricting $\tau_{i}(\cdot), \tau_{r}(\cdot)$, and $\tau_{0}(\cdot)$ to zero.

\subsection{Theoretical Consistency}

The translog variable cost function in all six models is consistent with theory or economically consistent if it satisfies the regularity properties of $c v(\cdot)$ in $w, z$, and q-listed along with their mathematical interpretation in Table 2. Theoretical consistency is important; in fact, it is fundamental, not only because it assures us that the variable cost function is wellbehaved in its arguments but also because duality theory does not apply to irregular economic models--underlying duality theorems assume theoretical consistency. Empirically, however, the translog or any other functional specification can fail to satisfy any property, particularly so if they are estimated with classical econometric methods. Hence, the attempt to treat these properties as maintained hypotheses, by imposing them directly on the translog variable cost function a priori is warranted-even though, in principle, they are testable hypotheses. This task, unfortunately, is not possible for all of the eleven properties for reasons to which the discussion now turns.

Regularity properties can be understood econometrically as restrictions derived from the theoretical model. The number of properties that can be directly imposed a priori on the specification of the variable cost function depends on the specification itself and the resulting functional structure for each property. In a Cobb-Douglas specification, ${ }_{1}^{19}$ for example, the mathematical complexity of the derivative consistency conditions listed in Table 2 is significantly less than for the translog specification. The Cobb-Douglas functional form is a simple albeit restrictive specification in which these properties can be imposed a priori using linear equality and inequality parametric constraints. This feature, unfortunately, is not shared by the translog functional form. The non-negativity, symmetry, and homogeneity properties pose no problem according to their mathematical

Table 2.- Regularity properties of the variable cost function ${ }^{\mathrm{a}}$

\begin{tabular}{|c|c|c|}
\hline No & Property & Mathematical Interpretationb \\
\hline 1 & Symmetry in $w$ & $\nabla_{w w} c v(\cdot)=\nabla_{w w} c v(\cdot)^{T}$ \\
\hline 2 & Non-negativity in $w$ & $c v(\cdot) \geq 0, \forall \boldsymbol{w} \geq 0_{n}$ \\
\hline 3 & Monotonicity in $w$ & $\nabla_{w} c v(\cdot) \geq 0_{n}$ \\
\hline 4 & First-Degree Homogeneity in $w$ & $\sum_{i=1}^{n} \frac{\partial c v(\cdot)}{\partial w_{i}} w_{i}=c v(\cdot)$ \\
\hline 5 & Concavity in $w$ & $\nabla_{w w} c v(\cdot) \mathrm{NSD}$ \\
\hline 6 & Non-negativity in $q$ & $c v(\cdot) \geq 0, \forall q \geq 0$ \\
\hline 7 & Monotonicity in $q$ & $\frac{\partial c v(\cdot)}{\partial q} \geq 0$ \\
\hline 8 & Symmetry in $z$ & $\nabla_{z z} c v(\cdot)=\nabla_{z z} c v(\cdot)^{T}$ \\
\hline 9 & Non-negativity in $z$ & $c v(\cdot) \geq 0, \forall \mathbf{z} \geq 0_{m}$ \\
\hline 10 & Non-increasingness in $z$ & $\nabla_{z} c v(\cdot) \leq 0_{m}$ \\
\hline 11 & Convexity in $z$ & $\nabla_{z z} c v(\cdot) \mathrm{PSD}$ \\
\hline a/ Table based on Hazilla and Kopp (1986). & \\
\hline b/ NSD stands for negative semidefinite and PSD for positive semidefinite.
\end{tabular}

interpretation. In fact, they are imposed a priori in each model to form part of its characteristics. The rest of the properties, however, are linear and nonlinear inequality constraints that depend on function parameters and exogenous variables, thus making it impossible to algebraically embed them in the translog specification. We cannot keep these properties as maintained hypotheses or test for them using classical econometrics. Before this fact, theoretical consistency is used in this work as diagnostics in order to verify whether this second set of properties are satisfied by each model a posteriori. ${ }^{20}$ 


\subsection{Estimation}

Each model is expressed as a seemingly unrelated regression (SUR) system of equations for estimation. This system involves the natural logarithm of $c v(\cdot)$, and the $n$ variable-factor derived share equations, of which $s_{i}$ is the $i$ th. If we account for the stochastic component of the data generation process by appending the additive disturbance terms $u_{c v}$ and $u_{s_{i}}$, respectively, a representative system for each model can be written for $t=1, \ldots, T$, as

$$
\begin{gathered}
\operatorname{lncv}(\cdot)=\alpha_{0}+\sum_{i=1}^{n} \alpha_{i} \ln w_{i t}+\frac{1}{2} \sum_{i=1}^{n} \sum_{j=1}^{n} \beta_{i j} \ln w_{i t} \ln w_{j t}+\sum_{r=1}^{m} \alpha_{r} \ln z_{r t}+\frac{1}{2} \sum_{r=1}^{m} \sum_{g=1}^{m} \beta_{r g} \ln z_{i t} \ln z_{g t}+\frac{1}{2} \sum_{i=1}^{n} \sum_{r=1}^{m} \beta_{i r} \ln w_{i t} \ln z_{r t} \\
+\alpha_{q} \ln q_{t}+\frac{1}{2} \beta_{q q}\left(\ln q_{t}\right)^{2}+\sum_{i=1}^{n} \beta_{i q} \ln w_{i t} \ln q_{t}+\sum_{r=1}^{m} \beta_{r q} \ln z_{r t} \ln q_{t}+\tau_{0 t}(\cdot)+\sum_{i=1}^{n} \tau_{i t}(\cdot) \ln w_{i}+\sum_{r=1}^{m} \tau_{r t}(\cdot) \ln z_{r t}+u_{c v_{t}} \ldots, \\
s_{1_{t}}=\alpha_{1}+\sum_{j=1}^{n} \beta_{1 j} \ln w_{j t}+\sum_{j=1}^{n} \beta_{1 r} \ln z_{r t}+\beta_{1 q} \ln q_{t}+\sum_{i=1}^{n} \frac{\partial \tau_{i t}(\cdot)}{\partial \ln w_{i t}} \ln w_{1 t}+u_{s_{1} t} \\
S_{2_{t}}=\alpha_{2}+\sum_{j=1}^{n} \beta_{2 j} \ln w_{j t}+\sum_{j=1}^{n} \beta_{2 r} \ln z_{r t}+\beta_{2 q} \ln q_{t}+\sum_{i=1}^{n} \frac{\partial \tau_{i t}(\cdot)}{\partial \ln w_{i t}} \ln w_{2 t}+u_{s_{2} t} \\
S_{n_{t}}=\alpha_{n}+\sum_{j=1}^{n} \beta_{n j} \ln w_{j t}+\sum_{j=1}^{n} \beta_{n r} \ln z_{r t}+\beta_{n q} \ln q_{t}+\sum_{i=1}^{n} \frac{\partial \tau_{i t}(\cdot)}{\partial \ln w_{i t}} \ln w_{n t}+u_{s_{n} t}
\end{gathered}
$$

where at $t$, the share of $x_{i}$ is algebraically derived as $s_{i}=\frac{\partial \ln c v(\cdot)}{\partial \ln w_{i}}$, since $s_{i}=\frac{\partial \ln c v(\cdot)}{\partial \ln w_{i}}=\frac{w_{i}}{\operatorname{cv}(\cdot)} \cdot \frac{\partial \operatorname{cv}(\cdot)}{\partial w_{i}}$, which by Shephard's lemma, ${ }^{21}$ can be shown to equal $\frac{w_{i} x_{i}}{\sum^{n} w_{j} x_{j}}, i=1, \ldots, n .{ }^{22}$ Also at $t, u_{c v}$ and $u_{s_{i}}$ are assumed to be normally distributed

$$
\sum_{j=1}^{n} w_{j} x_{j}
$$

asymptotically with zero mean, spherical, and contemporaneously correlated.

Models 2 through 6 are linear in the parameters as a result of the specification assumed for $\ln \tau_{0}(\cdot), \ln \tau_{i}(\cdot)$, and $\ln \tau_{r}(\cdot)$, in each case. Linearity provides for the possibility to rewrite the representative system in matrix form to facilitate estimation. Equation (15) can thus be expressed as follows:

$$
\left[\begin{array}{c}
\boldsymbol{I n c v} \\
\boldsymbol{s}_{1} \\
\vdots \\
\boldsymbol{s}_{\boldsymbol{n}}
\end{array}\right]=\left[\begin{array}{cccc}
\boldsymbol{x}_{c \boldsymbol{v}} & 0 & \cdots & 0 \\
0 & \boldsymbol{x}_{\boldsymbol{s}_{1}} & \cdots & 0 \\
\vdots & 0 & \ddots & \vdots \\
0 & 0 & \cdots & \boldsymbol{x}_{\boldsymbol{s}_{n}}
\end{array}\right]\left[\begin{array}{c}
\boldsymbol{\beta}_{c v} \\
\boldsymbol{\beta}_{s_{1}} \\
\vdots \\
\boldsymbol{\beta}_{s_{n}}
\end{array}\right]+\left[\begin{array}{c}
\boldsymbol{u}_{c v} \\
\boldsymbol{u}_{s_{1}} \\
\vdots \\
u_{s_{n}}
\end{array}\right]
$$

where $\boldsymbol{I n c v}, \boldsymbol{s}_{\boldsymbol{i}}, \boldsymbol{u}_{\boldsymbol{c}}$, and $\boldsymbol{u}_{\boldsymbol{s}_{i}}$ are $T$-order vectors, $\boldsymbol{x}_{\boldsymbol{c}}$ is a $\left(T \times k_{c v}\right)$-order matrix, $\boldsymbol{x}_{\boldsymbol{s}_{i}}\left(T \times k_{i}\right)$-order matrix, $\boldsymbol{\beta}_{\boldsymbol{c}}$ is a $\left(\boldsymbol{k}_{c v} \times 1\right)$-dimensional vector, and $\boldsymbol{\beta}_{\boldsymbol{s}_{1}}$ is a $\left(k_{i} \times 1\right)$-dimensional vector. Following Judge, et al. (1988), equation (16) can be rewritten, for simplicity, as

$$
\boldsymbol{Y}=\boldsymbol{X} \boldsymbol{\beta}+\boldsymbol{u}
$$

where $Y$ is a vertical concatenation of of $\boldsymbol{I n c \boldsymbol { v }}, \boldsymbol{s}_{1}, \boldsymbol{s}_{2}$, through $\boldsymbol{s}_{n} ; X$ is the design matrix of equation system (16); $\boldsymbol{\beta}$ is a vertical concatenation of $\boldsymbol{\beta}_{c \boldsymbol{v}}, \boldsymbol{\beta}_{\boldsymbol{s}_{1}}, \boldsymbol{\beta}_{s_{2}}, \ldots, \boldsymbol{\beta}_{\boldsymbol{s}_{n}}$; and $\boldsymbol{u}$ results from vertically concatenating $\boldsymbol{u}_{\boldsymbol{c}^{\prime}} \boldsymbol{u}_{\boldsymbol{s}_{1}^{\prime}} \boldsymbol{u}_{\boldsymbol{s}_{2}}, \ldots, \boldsymbol{u}_{\boldsymbol{s}_{n}}$. The dimensions of this super model are, respectively, $(\mathrm{mT} \times 1),(\mathrm{mT} \times \mathrm{k}),(\mathrm{k} \times 1)$, and $(m T \times 1)$, with $k=\sum_{i=1}^{m} k_{i}$

Models 2 through 6 are estimated using the iterative version of the SUR estimator developed by Zellner (1962). The criterion for iterative SUR or IZEF is $\Phi(\beta)=\operatorname{argmin}_{\beta}\left[\boldsymbol{u}^{\prime}(\hat{\Sigma} \otimes \boldsymbol{I})^{-1} \boldsymbol{u}\right]$, where $\Phi(\cdot)$ is the residual sum of squares function, $\hat{\boldsymbol{\Sigma}}$ is a consistent estimate of the contemporaneous covariance matrix $\boldsymbol{\Sigma}$, and $\boldsymbol{I}$ is the identity matrix. Function $\Phi(\cdot)$ is minimized by iterating on $\boldsymbol{\Sigma}$ - a recursive procedure in which, at every iteration, a new set of contemporaneous covariances is obtained from $\sigma_{i j} \frac{\left(\boldsymbol{Y}_{\boldsymbol{i}}-\boldsymbol{X}_{\boldsymbol{i}} \hat{\boldsymbol{\beta}}_{\boldsymbol{i}}\right)\left(\boldsymbol{Y}_{\boldsymbol{j}}-\boldsymbol{X}_{j} \hat{\boldsymbol{\beta}}_{\boldsymbol{j}}\right)}{T}$, where $\hat{\boldsymbol{\beta}}^{\prime}=\left(\hat{\boldsymbol{\beta}}_{1}^{\prime}, \hat{\boldsymbol{\beta}}_{2}^{\prime}, \ldots, \hat{\boldsymbol{\beta}}_{\boldsymbol{m}}^{\prime}\right)$ is the SUR estimator for $\boldsymbol{\beta}^{\prime}$, derived as $\hat{\boldsymbol{\beta}_{\text {ZEF }}}=\left[\boldsymbol{X}^{\boldsymbol{T}}\left(\hat{\mathbf{O}}^{-1} \otimes \boldsymbol{I}\right) \boldsymbol{X}\right]^{-1} \boldsymbol{X}^{\boldsymbol{T}}\left(\hat{\mathbf{O}}^{-1} \otimes \boldsymbol{I}\right) \boldsymbol{Y}$, and $\boldsymbol{i}=1,2, \ldots, m$, and $\boldsymbol{j}=1,2, \ldots, m$. At every iteration, $\boldsymbol{\Sigma}$ is used to form a new estimator for $\boldsymbol{\beta}$ until convergence. ${ }^{23}$ Iterative SUR is an appropriate estimator to derive the estimates for $\boldsymbol{\beta}$ in these models because it applies to multivariate linear models and provides for cross-equations restrictions and contemporaneous correlation implied by $\boldsymbol{\Sigma}$. In addition, IZEF estimates, as shown by Kmenta and Gilbert (1968), are numerically equivalent to those obtained under 
maximum likelihood estimation. Its application, moreover, is relatively straightforward since $\Phi(\cdot)$ is quadratic and admits to a closed-form solution for $\boldsymbol{\Sigma}$.

Model 1, in contrast, is not linear in the parameters. The reason for this nonlinearity is the same as that for the linearity of models 2 through 6: the specification assumed for $\ln \tau_{0}(\cdot), \ln \tau_{i}(\cdot)$, and $\ln \tau_{r}(\cdot)$ [see equations (7), (8), and (9)]. Model 1 is estimated accordingly by nonlinear maximum likelihood (ML). To this effect, the representative system can be rewritten as

$$
\boldsymbol{Y}=F(\boldsymbol{X} \boldsymbol{\beta})+\boldsymbol{u}
$$

where, also by assumption, $\boldsymbol{u} \sim N\left(\mathbf{0}_{m T}, \boldsymbol{\Sigma}_{m} \otimes \boldsymbol{I}_{T}\right)$ asymptotically and satisfies the equalities of rigor for $u_{i}$ and $u_{j}$ at $t^{24} T$ he criterion under nonlinear ML estimation consists of choosing estimates for $\boldsymbol{\beta}$ and $\boldsymbol{\Sigma}$ that would maximize the probability of obtaining $Y$ under a multivariate normal specification. These estimates are the values that maximize the log-likelihood function $L(\boldsymbol{\beta}, \boldsymbol{\Sigma})=-\frac{T m}{2} \ln 2 \pi \frac{1}{2} \ln |\boldsymbol{\Sigma}|-\frac{1}{2} \operatorname{tr}\left[\Theta \times \Sigma^{-1}\right]$, where $\operatorname{tr}$ is the trace operator and $\Theta$ is an $(m \times m)$ matrix, with $\boldsymbol{u}_{\boldsymbol{i}} \boldsymbol{u}_{\boldsymbol{j}}$ is the $\boldsymbol{i}$ th th element. They are obtained by concentrating $L(\cdot)$ into an exclusive function of $\boldsymbol{\beta}$, which is possible by obtaining an analytical expression for the ML estimator of $\boldsymbol{\Sigma}$ as a function of $\boldsymbol{\beta}$. In this regard, it would be more convenient to differentiate $L(\cdot)$ with respect to $\boldsymbol{\Sigma}^{-1}$ rather than $\boldsymbol{\Sigma}$. It can be shown that $\frac{\partial \ln \left|\boldsymbol{\Sigma}^{-1}\right|}{\partial \boldsymbol{\Sigma}^{-1}}=\boldsymbol{\Sigma}$ and $\frac{\partial \operatorname{tr}\left[\Theta \times \boldsymbol{\Sigma}^{-1}\right]}{\partial \boldsymbol{\Sigma}^{-1}}=\Theta$. Since $-\frac{\mathrm{T}}{2} \ln |\boldsymbol{\Sigma}|=\frac{\mathrm{T}}{2} \ln \left|\boldsymbol{\Sigma}^{-1}\right|$, one has $\frac{\partial \mathrm{L}}{\partial \boldsymbol{\Sigma}^{-1}} \frac{\mathrm{T}}{2} \boldsymbol{\Sigma}-\frac{1}{2} \Theta$. Solving for $\boldsymbol{\Sigma}$ as one sets $\frac{\partial \mathrm{L}}{\partial \boldsymbol{\Sigma}^{-1}}=0$ yields its estimator $\tilde{\boldsymbol{\Sigma}}=\frac{\Theta}{\mathrm{T}}$. The concentrated log-likelihood function is obtained by substituting $\boldsymbol{\Sigma}$ back into $L(\cdot)$; that is, $L^{\prime}(\boldsymbol{\beta})=\mathrm{k}-\frac{\mathrm{T}}{2} \ln |\Theta|$, where $\boldsymbol{k}$ is a constant. Hence, the nonlinear ML estimator for $\boldsymbol{\beta}$ is that value of $\boldsymbol{\beta}$ that minimizes $|\boldsymbol{\Theta}|$. Note, in concluding, that $\Theta$ is a function of $\boldsymbol{\beta}$, which implies that $\boldsymbol{\Sigma}$ is evaluated at $\boldsymbol{\beta}$. The nonlinear ML estimator is consistent, uniform, and asymptotically normal. ${ }^{25}$

Model 1 is difficult to estimate inasmuch as no closed-form solution exists under nonlinear estimation for the optimization of the objective function before any $\boldsymbol{\Sigma}$ estimate. To this effect, the Davidson-Fletcher-Powell (DFPMIN) algorithm is employed as computational environment in which the objective functions are to be optimized. ${ }^{26}$ This algorithm is a variable metric or quasiNewtonian method by which it is possible to derive analytical expressions for nonlinear parameter estimates. As any other numerical method in charge of systematically searching for a solution of a nonlinear optimization problem, DFPMIN requires initial conditions to operate. Selection of these conditions is very important because whether an algorithm converges or not can depend on said values. Unfortunately, there does not exist a transparent way of choosing initial conditions. Although economic theory can sometimes provide guidance, selecting initial conditions typically boils down to a judgement call by the practicing econometrician. A grid search and the nonlinear SUR estimation method of Gallant (1975) are used as preliminary procedures to develop nonlinear ML estimates in the present case. Specifically, a grid search is used to obtain initial estimates for $\lambda{ }^{27}$ The second step consists of using IZEF to estimate the remaining parameters of the model. The third step consists of employing these working estimates (including that for $\lambda$ ), as initial values, to obtain nonlinear SUR estimates. ${ }^{28}$ These estimates comprise the initial values for the nonlinear ML parameters in the next and final step. ${ }^{29}$

\section{ANALYSIS OF EMPIRICAL RESULTS}

The present section reports and analyzes the empirical results of this research. The results are presented as two batteries of numbers and preceded by a review of the data. The first battery sets the stage and involves parameter estimates and asymptotic standard errors, hypothesis tests, and regularity diagnostics. The second battery of numbers involves rent estimates as well as response surface estimates which are used to evaluate the sensitivity of the rent to the empirical specification of $c v(\cdot)$. The sensitivity analysis provides for the possibility to assess whether alternative sets of assumptions on model characteristics translate into statistically different rent estimates and whether research decisions and regularity affect the informational content of rent as a measure of resource scarcity. ${ }^{30}$

\subsection{Data}

The data used in this study are those from Lasserre and Ouellette. They consist of time-series price and quantity aggregates for labor $(l)$, energy $(e)$, materials $(m)$, capital $(k)$, and resource reserves $(n)$ for the Canadian asbestos industry (1953-1985). They also include industry output $(q)$, variable cost, and the cost shares for said factor inputs.

Production is thus assumed to take place under a technologically feasible economic combination of variable and quasi-fixed inputs. Inputs $l, e$ and $m$ are modeled as variable 


\section{Figure 1. Capital, reserves and output Canadian asbestos industry, 1953-1985}

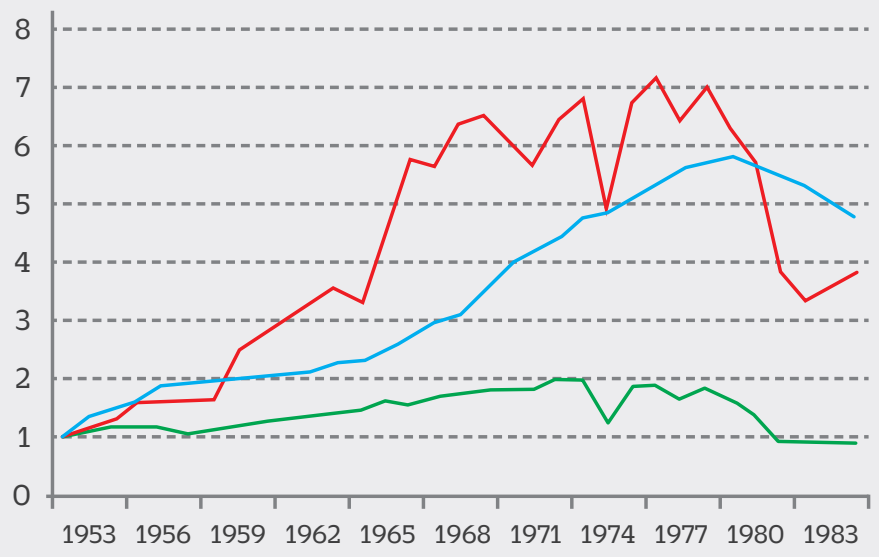

- Capital - Reserves Output

while $\boldsymbol{k}$ and $\boldsymbol{n}$ are treated as quasi-fixed. ${ }^{31}$ Figure 1 provides casual evidence on the quasi-fixity of $\boldsymbol{k}$. There are two clear tendencies in the $k$ series over the period of study. Capital tends to be consistent with $q$ as long as $q$ remains constant or rises. Capital, however, fails to adjust to sharp drops in $q$. From the data it can be seen that the variable inputs, in contrast, largely follow production as expected. It is thus apparent that a sound description of the technology in the Canadian asbestos industry must involve $k$ as a rigid downward but flexible upward input. Input $n$ is assumed to be quasifixed in the spirit of Pindyck (1978).

\subsection{Estimates, Statistics, and Inference}

Parameter estimates for each of the models are reported in tables 3, 5, and 7. Table 3 presents parameter estimates for the basic technology while Table 5 exclusively exhibits the parameters that relate to technical change. Table 4 and Table 6 report, respectively, asymptotic standard errors for this technology and for the parameters of technical change. Table 7 reports parameter estimates that relate to labor. These latter estimates were derived indirectly, as opposed to being (directly) estimated, because in each of the six models the share equation for $l$ was excluded from the SUR equation system as one of the requirements for making the systems econometrically operational.

The number of estimated parameters per model depends on the assumptions on scale and technical change. In particular, the number of parameters for the basic technology varies according to scale assumptions: in models 3 and 5 homotheticity implies a basic technology that is described with seventeen unrestricted parameters, whereas the assumption of non-homotheticity in models 1, 2, 4, and 6, implies a basic technology that can be described with twenty-one. The number of parameters related to technical change depends on whether a dynamic specification change is considered and on whether technical change is modeled as factor biased or Hicks-neutral.

In Model 1, for example, a dynamic adjustment mechanism to factor-biased technical change was adopted for which twentyone unrestricted parameters are used in addition to a Koyck constant $\lambda$. For the rest of the models, save the sixth, a static adjustment mechanism to technical change was adopted instead for which two unrestricted parameters are used if said change is Hicks-neutral and six if it is factor-biased. Thus, Model 1 involves forty-three parameters; Model 2 involves twentyseven; twenty-three for Model 3 and Model 4; and nineteen and twenty-one for Model 5 and Model 6, respectively.

An often interesting question involves the consistency of the data to research decisions. Whether the data are consistent with one hypothesis or another is equivalent to asking whether a particular set of parameter restrictions is supported empirically. Statistical inference on the validity of parameter restrictions in a SUR system of equations can be conducted in several ways that are asymptotically equivalent. The most frequently used test statistic for this purpose, however, is the likelihood ratio, which can be expressed as $\omega=2\left(\ln \frac{L_{0}}{L_{1}}\right)$, where $L_{0}$ is the value of the sample maximized log-likelihood function under the constrained model (i.e., that subject to the parametric restrictions), and $L_{1}$ is its analog for the unconstrained model..$^{32}$ The likelihood ratio is distributed asymptotically as a $\chi^{2}$ random variable, with degrees of freedom equal to the difference between the number of free parameters estimated in the unconstrained and constrained models under the null hypothesis $\boldsymbol{H}_{0}=\boldsymbol{\beta}=\boldsymbol{\beta}_{0}$. Estimates for $L_{1}$ are reported in Table 8. Likelihood ratio estimates for hypotheses of interest are reported in Table 9.

The first hypothesis test confronts the assumption of a dynamic adjustment 
Table 3.-- Parameter estimates for the basic technology

\begin{tabular}{|c|c|c|c|c|c|c|}
\hline \multirow{2}{*}{ Parameters } & \multicolumn{6}{|c|}{ Models $^{\mathrm{a}}$} \\
\hline & 1 & 2 & 3 & 4 & 5 & 6 \\
\hline$\alpha_{0}$ & 15.2900 & 10.5555 & 10.5528 & 10.5232 & 10.5189 & 10.5262 \\
\hline$\alpha_{e}$ & 0.1126 & 0.0898 & 0.0874 & 0.1018 & 0.1052 & 0.1012 \\
\hline$\alpha_{m}$ & 0.2416 & 0.2510 & 0.2477 & 0.2511 & 0.2458 & 0.2515 \\
\hline$\alpha_{k}$ & -0.1569 & 1.9773 & 3.0256 & 0.4877 & 0.2573 & 0.1702 \\
\hline$\alpha_{s}$ & 0.2485 & 0.5057 & 0.6760 & 0.1810 & 0.0229 & -0.0476 \\
\hline$\alpha_{q}$ & 0.4993 & 0.8915 & 1.1683 & 0.6090 & 0.8448 & 0.6173 \\
\hline$\beta_{e e}$ & 0.0353 & 0.1250 & 0.1552 & 0.1042 & 0.1786 & 0.0918 \\
\hline$\beta_{e m}$ & 0.0926 & -0.0882 & -0.1463 & -0.0359 & -0.1764 & -0.0104 \\
\hline$\beta_{e k}$ & 0.0078 & -0.0063 & -0.0200 & 0.0208 & -0.0088 & 0.0287 \\
\hline$\beta_{e s}$ & 0.0090 & 0.0170 & -0.0022 & 0.0435 & 0.0180 & 0.0448 \\
\hline$\beta_{e q}$ & -0.0203 & -0.0505 & $\ldots$ & -0.0971 & $\ldots$ & -0.1085 \\
\hline$\beta_{m m}$ & -0.0746 & 0.1083 & 0.2032 & 0.0213 & 0.2076 & 0.0089 \\
\hline$\beta_{m k}$ & 0.0146 & 0.0259 & 0.0530 & -0.0038 & 0.0579 & -0.0098 \\
\hline$\beta_{m s}$ & 0.0370 & 0.0304 & 0.0343 & 0.0248 & 0.0203 & 0.0302 \\
\hline$\beta_{m q}$ & 0.0711 & 0.0496 & $\ldots$ & 0.0949 & $\ldots$ & 0.1043 \\
\hline$\beta_{k k}$ & 1.8440 & 1.3825 & 2.5252 & 0.0385 & 0.2490 & 0.0505 \\
\hline$\beta_{s k}$ & -0.4081 & 0.4486 & 0.4038 & -0.1334 & 0.0865 & -0.0680 \\
\hline$\beta_{k q}$ & 0.6672 & -0.2202 & $\ldots$ & 0.2334 & $\ldots$ & 0.2267 \\
\hline$\beta_{s s}$ & 0.3757 & -0.0036 & 0.4263 & -0.1189 & 0.0560 & -0.0959 \\
\hline$\beta_{s q}$ & -0.4050 & 0.5763 & $\ldots$ & 0.3547 & $\ldots$ & 0.4160 \\
\hline$\beta_{q q}$ & -0.1250 & -2.1268 & -1.6363 & -1.1288 & -0.7127 & -0.9479 \\
\hline
\end{tabular}

a/ ... indicates parameter not applicable for estimated model.

mechanism to technical change to its static alternative. It relates Model 1 to the rest of the models. The next four hypotheses address alternative forms of scale and technical change, including the absence of technical change. These hypotheses relate Model 2 to models 3, 4, 5, and 6. In reviewing the information of Table 9, notice that models 3, 4, 5, and 6 are restricted versions of Model 2, which is itself a restricted case of Model 1.

According to estimates, we would reject the absence of a dynamic adjustment mechanism to technical change. We, however, fail to reject the null hypothesis of a homothetic technology (test 2). ${ }^{33}$ We also would reject the absence of technical change 
Table 4.-Asymptotic standard errors for the basic technology

\begin{tabular}{|c|c|c|c|c|c|c|}
\hline \multirow{2}{*}{ Parameters } & \multicolumn{6}{|c|}{ Models $^{\mathrm{b}}$} \\
\hline & 1 & 2 & 3 & 4 & 5 & 6 \\
\hline$\alpha_{0}$ & 1.8030 & 0.0297 & 0.0274 & 0.0284 & 0.0275 & 0.0329 \\
\hline$\alpha_{e}$ & 0.0097 & 0.0067 & 0.0067 & 0.0045 & 0.0045 & 0.0047 \\
\hline$\alpha_{m}$ & 0.0331 & 0.0148 & 0.0136 & 0.0091 & 0.0082 & 0.0093 \\
\hline$\alpha_{k}$ & 0.4728 & 0.7029 & 0.6851 & 0.2902 & 0.1195 & 0.1134 \\
\hline$\alpha_{s}$ & 0.1641 & 0.1830 & 0.1857 & 0.1360 & 0.1472 & 0.1143 \\
\hline$\alpha_{q}$ & 0.2796 & 0.3026 & 0.1746 & 0.2406 & 0.1489 & 0.2592 \\
\hline$\beta_{e e}$ & 0.0168 & 0.0226 & 0.0214 & 0.0184 & 0.0231 & 0.0153 \\
\hline$\beta_{e m}$ & 0.0192 & 0.0280 & 0.0245 & 0.0220 & 0.0237 & 0.0185 \\
\hline$\beta_{e k}$ & 0.0273 & 0.0120 & 0.0120 & 0.0113 & 0.0131 & 0.0112 \\
\hline$\beta_{e s}$ & 0.0128 & 0.0140 & 0.0118 & 0.0121 & 0.0115 & 0.0122 \\
\hline$\beta_{e q}$ & 0.0149 & 0.0202 & $\ldots$ & 0.0187 & $\ldots$ & 0.0187 \\
\hline$\beta_{m m}$ & 0.1042 & 0.0599 & 0.0543 & 0.0526 & 0.0463 & 0.0557 \\
\hline$\beta_{m k}$ & 0.0996 & 0.0251 & 0.0244 & 0.0231 & 0.0232 & 0.2370 \\
\hline$\beta_{m s}$ & 0.0411 & 0.0299 & 0.0167 & 0.0248 & 0.0143 & 0.0255 \\
\hline$\beta_{m q}$ & 0.0568 & 0.0417 & $\ldots$ & 0.0369 & $\ldots$ & 0.0377 \\
\hline$\beta_{k k}$ & 1.1430 & 0.8332 & 0.7838 & 0.3430 & 0.2705 & 0.3153 \\
\hline$\beta_{s k}$ & 0.3691 & 0.4063 & 0.1923 & 0.3072 & 0.1626 & 0.3017 \\
\hline$\beta_{k q}$ & 0.5774 & 0.4681 & $\ldots$ & 0.4102 & $\ldots$ & 0.3932 \\
\hline$\beta_{s s}$ & 0.3447 & 0.3929 & 0.2050 & 0.3279 & 0.1271 & 0.3362 \\
\hline$\beta_{s q}$ & 0.5659 & 0.5483 & $\ldots$ & 0.5000 & $\ldots$ & 0.4911 \\
\hline$\beta_{q q}$ & 0.9556 & 0.8512 & 0.4326 & 0.7553 & 0.3485 & 0.7378 \\
\hline
\end{tabular}

a/ Standard errors for model 1 are square roots of the diagonal elements of minus the expected vale of the information matrix for nonlinear maximum likelihood estimation, while for models 2 through 6 , they are similarly derived from $\left[\boldsymbol{X}^{T}\left(\boldsymbol{\Sigma}^{-1} \otimes I\right)^{-1} \boldsymbol{X}\right]$

b/... indicates parameter not applicable for estimated model.

altogether (test 3), but fail to reject the absence of factor-biased technical change (test 4). Here the tests suggest the Hicksneutral form of technical change. This is further supported by the fact that estimates reject the assumption of a homothetic technology subject to factor-biased technical change (test 5). It can therefore be concluded in terms of $w$ for the last four tests that choice of a homothetic variable cost function subject to Hicks-neutral technical change over its non-homothetic similar might be more adequate for describing the technology in the Canadian asbestos industry for the period of study.

A second issue that merits discussion in the context of estimation of and inference in SUR equation systems concerns stacking and contemporaneous correlation among disturbance terms. Seemingly unrelated regression is justified by the gains in efficiency derived from accounting for contemporaneous correlation among disturbance terms. 
Table 5.-Parameter estimates for technical change

\begin{tabular}{|c|c|c|c|c|c|c|}
\hline \multirow{2}{*}{ Parameters } & \multicolumn{6}{|c|}{ Models $^{\mathrm{b}}$} \\
\hline & 1 & 2 & 3 & 4 & 5 & 6 \\
\hline \multicolumn{7}{|l|}{ Neutral change } \\
\hline$\alpha_{t}$ & $\ldots$ & 0.8089 & 1.2641 & 0.1224 & 0.0336 & ... \\
\hline$\beta_{t t}$ & 0.0014 & 0.8115 & 1.3493 & 0.0396 & 0.0000 & ... \\
\hline$\beta_{p}$ & 0.3008 & $\cdots$ & $\cdots$ & $\cdots$ & $\cdots$ & ... \\
\hline \multicolumn{7}{|l|}{ Biased change } \\
\hline$\beta_{e t}$ & 0.0035 & 0.0185 & 0.0236 & ... & $\ldots$ & $\ldots$ \\
\hline$\beta_{e s}$ & 0.0039 & 0.0033 & 0.0024 & $\ldots$ & $\cdots$ & ... \\
\hline$\beta_{k t}$ & 0.0300 & 1.2429 & 2.0503 & $\ldots$ & $\ldots$ & ... \\
\hline$\beta_{s t}$ & 0.0135 & 0.3897 & 0.5662 & $\ldots$ & $\ldots$ & $\ldots$ \\
\hline$v_{e e}$ & 0.0669 & ... & $\ldots$ & $\ldots$ & $\ldots$ & ... \\
\hline$v_{e m}$ & 0.0075 & ... & $\cdots$ & $\cdots$ & $\ldots$ & $\ldots$ \\
\hline$v_{m m}$ & 0.0001 & ... & ... & ... & ... & $\ldots$ \\
\hline$v_{e q}$ & 0.0223 & $\ldots$ & $\ldots$ & $\ldots$ & $\ldots$ & ... \\
\hline$v_{e k}$ & 0.0295 & $\ldots$ & $\ldots$ & $\ldots$ & $\ldots$ & $\ldots$ \\
\hline$v_{e s}$ & 0.0215 & $\ldots$ & $\ldots$ & $\ldots$ & $\ldots$ & $\ldots$ \\
\hline$v_{m k}$ & 0.0039 & $\ldots$ & $\ldots$ & ... & $\ldots$ & .. \\
\hline$v_{m s}$ & 0.0279 & $\ldots$ & $\ldots$ & ... & ... & $\ldots$ \\
\hline$v_{m q}$ & 0.0033 & $\ldots$ & $\ldots$ & $\ldots$ & $\ldots$ & $\ldots$ \\
\hline$v_{k k}$ & 0.3313 & $\ldots$ & $\ldots$ & $\ldots$ & $\ldots$ & ... \\
\hline$v_{k s}$ & 0.1554 & ... & $\ldots$ & $\ldots$ & $\ldots$ & ... \\
\hline$v_{k q}$ & 0.0523 & ... & $\ldots$ & $\ldots$ & $\ldots$ & $\ldots$ \\
\hline$v_{s s}$ & 0.0894 & $\ldots$ & $\ldots$ & $\ldots$ & $\ldots$ & ... \\
\hline$v_{s q}$ & 0.0094 & $\ldots$ & $\ldots$ & $\ldots$ & ... & $\cdots$ \\
\hline$v_{q q}$ & 0.1648 & $\ldots$ & $\ldots$ & $\ldots$ & $\ldots$ & $\ldots$ \\
\hline \multicolumn{7}{|l|}{ Koyck Constant } \\
\hline$\lambda$ & 0.4592 & $\ldots$ & $\ldots$ & $\ldots$ & $\ldots$ & $\ldots$ \\
\hline
\end{tabular}

a/ ... indicates parameter not applicable for estimated model.

Contemporaneous correlation is often assumed a priori, though it is a testable hypothesis. If it does not exist, then using SUR estimation methods is pointless because any of the participating equations can be efficiently estimated separately by ordinary least squares or any other single-equation estimator. Note, however, that this is true from a statistical point of view. There are cases in which contemporaneous correlation among disturbance terms need not be present to justify stacking nor in consequence the use of these methods. A case in point involves the presence of cross-equation restrictions imposed by economic theory. In applied economics, in effect, the use of these methods is not justified on statistical grounds exclusively. Such a fact, however, does not diminish the merit in testing whether the use of these methods is warranted statistically in applied economic work. In this study, therefore, the presence of contemporaneous correlation was 
Table 6.-Asymptotic standard errors for technical change ${ }^{a}$

\begin{tabular}{|c|c|c|c|c|c|c|}
\hline \multirow{2}{*}{ Parameters } & \multicolumn{6}{|c|}{ Models $^{\mathrm{b}}$} \\
\hline & 1 & 2 & 3 & 4 & 5 & 6 \\
\hline \multicolumn{7}{|l|}{ Neutral change } \\
\hline$\alpha_{t}$ & $\ldots$ & 0.2973 & 0.2837 & 0.1282 & 0.0139 & $\ldots$ \\
\hline$\beta_{t t}$ & 0.0046 & 0.3803 & 0.3432 & 0.0496 & 0.0006 & $\ldots$ \\
\hline$\beta_{p}$ & 0.1144 & $\ldots$ & $\ldots$ & $\cdots$ & $\ldots$ & $\ldots$ \\
\hline \multicolumn{7}{|l|}{ Biased change } \\
\hline$\beta_{e t}$ & 0.0017 & 0.0074 & 0.0071 & $\ldots$ & $\ldots$ & $\ldots$ \\
\hline$\beta_{e s}$ & 0.0048 & 0.0164 & 0.1420 & $\ldots$ & $\ldots$ & $\ldots$ \\
\hline$\beta_{k t}$ & 0.0568 & 0.5661 & 0.5192 & $\ldots$ & $\ldots$ & $\ldots$ \\
\hline$\beta_{s t}$ & 0.0305 & 0.2124 & 0.1824 & $\ldots$ & $\ldots$ & $\ldots$ \\
\hline$v_{e e}$ & 0.0144 & $\ldots$ & $\ldots$ & $\ldots$ & $\ldots$ & $\ldots$ \\
\hline$v_{e m}$ & 0.0257 & $\ldots$ & $\ldots$ & $\ldots$ & $\ldots$ & $\ldots$ \\
\hline$v_{m m}$ & 0.0122 & $\ldots$ & $\ldots$ & $\ldots$ & $\ldots$ & $\ldots$ \\
\hline$v_{e q}$ & 0.0080 & $\ldots$ & $\ldots$ & $\ldots$ & $\ldots$ & $\ldots$ \\
\hline$v_{e k}$ & 0.0134 & $\ldots$ & $\ldots$ & $\ldots$ & $\ldots$ & $\ldots$ \\
\hline$v_{e s}$ & 0.0800 & $\ldots$ & $\ldots$ & $\ldots$ & $\ldots$ & $\ldots$ \\
\hline$v_{m k}$ & 0.0426 & $\ldots$ & $\ldots$ & $\ldots$ & $\ldots$ & $\ldots$ \\
\hline$v_{m s}$ & 0.0312 & $\ldots$ & $\ldots$ & $\ldots$ & $\ldots$ & $\ldots$ \\
\hline$v_{m q}$ & 0.0565 & $\ldots$ & $\ldots$ & $\ldots$ & $\ldots$ & $\ldots$ \\
\hline$v_{k k}$ & 0.2424 & $\ldots$ & $\ldots$ & $\ldots$ & $\ldots$ & ... \\
\hline$v_{k s}$ & 0.1691 & $\ldots$ & $\ldots$ & $\ldots$ & $\ldots$ & $\ldots$ \\
\hline$v_{k q}$ & 0.2505 & $\ldots$ & $\ldots$ & $\ldots$ & $\ldots$ & $\ldots$ \\
\hline$v_{s s}$ & 0.2134 & $\ldots$ & $\ldots$ & $\cdots$ & $\ldots$ & $\ldots$ \\
\hline$v_{s q}$ & 0.4039 & $\ldots$ & $\ldots$ & $\ldots$ & $\ldots$ & $\ldots$ \\
\hline$v_{q q}$ & 0.8628 & $\ldots$ & $\ldots$ & $\ldots$ & $\ldots$ & $\ldots$ \\
\hline \multicolumn{7}{|l|}{ Koyck Constant } \\
\hline$\lambda$ & 0.0007 & $\ldots$ & $\ldots$ & $\ldots$ & $\ldots$ & $\ldots$ \\
\hline
\end{tabular}

a/ Standard errors for model 1 are square roots of the diagonal elements of minus the expected vale of the information matrix for nonlinear maximum likelihood estimation, while for models 2 through 6 , they are similarly derived from $\left[\boldsymbol{X}^{T}\left(\Sigma^{-1} \otimes I\right)^{-1} \boldsymbol{X}\right]$

b/ ... indicates parameter not applicable for estimated model.

tested in order to see if the decision of having used SUR estimation methods was sound from a statistical viewpoint.

Statistical justification for these methods can be derived by testing whether $\sigma_{i j}=0$ An appropriate test statistic for this task is the Breusch-Pagan Lagrange multiplier, defined for the general case of $n$ equations as $v=T \sum_{i=2}^{n} \sum_{j=1}^{i-1} \frac{\sigma_{i j}^{2}}{\sigma_{i i} \sigma_{j j}}$, where $T$ is the total number of observations and $\sigma_{i j}$ is the contemporaneous covariance between the $i$ th and $j$ th equations. Under $H_{0}, v$ has an asymptotic $\chi^{2}$ distribution with $\frac{n(n-1)}{2}$ degrees of freedom. 
Table 7.-Labor parameter estimates

\begin{tabular}{|c|c|c|c|c|c|c|}
\hline \multirow{2}{*}{ Parameters } & \multicolumn{6}{|c|}{ Models $^{a}$} \\
\hline & 1 & 2 & 3 & 4 & 5 & 6 \\
\hline$\alpha_{1}$ & 0.6458 & 0.6592 & 0.6648 & 0.6471 & 0.6491 & 0.6473 \\
\hline$\beta_{e l}$ & 0.1279 & 0.0368 & 0.0089 & 0.0682 & 0.0022 & 0.0814 \\
\hline$\beta_{m l}$ & 0.0180 & 0.0201 & 0.0569 & 0.0146 & 0.0312 & 0.0015 \\
\hline$\beta_{l l}$ & 0.1459 & 0.0569 & 0.0659 & 0.0536 & 0.0335 & 0.0798 \\
\hline$\beta_{l k}$ & 0.0224 & 0.0196 & 0.0330 & 0.0170 & 0.0491 & 0.0188 \\
\hline$\beta_{l s}$ & 0.0461 & 0.0474 & 0.0322 & 0.0683 & 0.0383 & 0.0750 \\
\hline$\beta_{l q}$ & 0.0508 & 0.0009 & $\ldots$ & 0.0023 & $\ldots$ & 0.0042 \\
\hline$\beta_{l t}$ & 0.0004 & 0.0153 & 0.0212 & $\ldots$ & $\ldots$ & $\ldots$ \\
\hline$v_{e l}$ & 0.0594 & $\ldots$ & $\ldots$ & $\ldots$ & $\ldots$ & $\ldots$ \\
\hline$v_{m l}$ & 0.0140 & $\ldots$ & $\ldots$ & $\ldots$ & $\ldots$ & $\ldots$ \\
\hline$v_{l l}$ & 0.0734 & $\ldots$ & $\ldots$ & $\ldots$ & $\ldots$ & $\ldots$ \\
\hline$v_{l q}$ & 0.0262 & $\ldots$ & $\ldots$ & $\ldots$ & $\ldots$ & $\ldots$ \\
\hline$v_{l k}$ & 0.0038 & $\ldots$ & $\ldots$ & $\ldots$ & $\ldots$ & $\ldots$ \\
\hline
\end{tabular}

a/ ... indicates parameter not applicable for estimated model.

Table 8.-Log likelihood function and Breusch-Pagan Lagrange multiplier estimates

\begin{tabular}{|c|c|c|}
\hline Models & $\begin{array}{c}\text { Log-likelihood } \\
\text { function }\end{array}$ & $\begin{array}{c}\text { Breusch-Pagan } \\
\text { Lagrange multiplier }\end{array}$ \\
\hline 1 & 255.76 & 46.68 \\
\hline 2 & 224.70 & 27.34 \\
\hline 3 & 221.70 & 14.68 \\
\hline 4 & 220.70 & 44.50 \\
\hline 5 & 213.10 & 17.42 \\
\hline 6 & 217.50 & 47.33 \\
\hline
\end{tabular}

In the context of the current three-equation SUR system, the null and alternative hypotheses for each model are, respectively, $H_{0}: \sigma_{12}=\sigma_{13}=\sigma_{23}=0$, and $H_{1}$ : at least one covariance is not zero. If $\kappa_{i j}^{2}=\frac{\sigma_{i j}^{2}}{\sigma_{i j} \sigma_{i j}}$, then $v=T\left(\kappa_{21}^{2}+\kappa_{31}^{2}+\kappa_{32}^{2}\right)$. Under $H_{0}, v$ has an asymptotic $\chi^{2}$ distribution with 3 degrees of freedom. Hence, $H_{0}$ is rejected if $v$ is greater than the critical value from a $\chi_{(3)}^{2}$ distribution for a pre-specified level of significance. Relevant estimates for are reported in Table 8 . At the 5 percent level of significance the critical value from $\chi_{(3)}^{2}$ is 7.31 , so the null hypothesis of no contemporaneous correlation can be strongly rejected for every model. 
Table 9.-Statistical inference on alternative scale and technical-change assumptions

\begin{tabular}{|c|c|c|c|c|c|}
\hline Hypotheses tests & $\begin{array}{l}\text { Unconstrained } \\
\text { log-likelihood } \\
\text { function }\end{array}$ & $\begin{array}{l}\text { Constrained } \\
\text { log-likelihood } \\
\text { function }\end{array}$ & $\begin{array}{l}\text { Likelihood } \\
\text { ratio }\end{array}$ & $\begin{array}{l}\text { Number of } \\
\text { constrained } \\
\text { parameters }\end{array}$ & $\begin{array}{l}\chi^{2} \text { critical } \\
\text { value at } \\
\alpha=0.05^{a}\end{array}$ \\
\hline 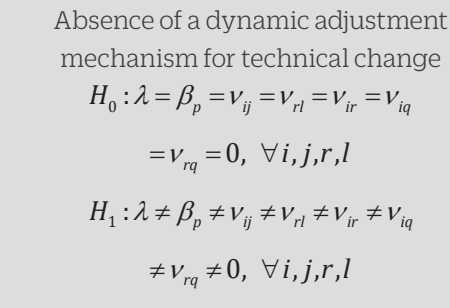 & 255.76 & 224.70 & 62.12 & 16 & 26.30 \\
\hline $\begin{array}{l}\text { Absence of non-homotheticity } \\
\qquad \begin{array}{c}H_{0}: \beta_{i q}=\beta_{r q}=0, \forall i, r \\
H_{1}: \beta_{i q} \neq \beta_{r q} \neq 0, \forall i, r\end{array}\end{array}$ & 224.70 & 221.70 & 6.00 & 4 & 9.49 \\
\hline $\begin{array}{l}\text { Absence of technical change } \\
H_{0}: \beta_{i t}=\beta_{r t}=\alpha_{t}=\beta_{t t}=0, \forall i, r \\
H_{1}: \beta_{i t} \neq \beta_{r t} \neq \alpha_{t} \neq \beta_{t t} \neq 0, \forall i, r\end{array}$ & 224.70 & 217.50 & 14.00 & 6 & 12.59 \\
\hline $\begin{array}{l}\text { Absence of factor-biased technical cha } \\
\qquad \begin{array}{c}H_{0}: \beta_{i t}=\beta_{r t}=0, \forall i, r \\
H_{1}: \beta_{i t} \neq \beta_{r t} \neq 0, \forall i, r\end{array}\end{array}$ & 224.70 & 220.70 & 4.00 & 4 & 9.49 \\
\hline $\begin{array}{l}\text { Absence of non-homotheticity and } \\
\text { factor-biased technical change } \\
H_{0}: \beta_{i q}=\beta_{r q}=\beta_{i t}=\beta_{r t}=0, \forall i, r \\
H_{1}: \beta_{i q} \neq \beta_{r q} \neq \beta_{i t} \neq \beta_{r t} \neq 0, \forall i, r\end{array}$ & 224.70 & 213.10 & 23.20 & 8 & 15.51 \\
\hline
\end{tabular}

\subsection{Regularity Diagnostics}

Table 10 reports the number of observations at which each of the models of Table 2 violates economic theory. These entries serve as regularity diagnostics. In Table 10 diagnostics are based on $n$ and $k$ as implied by temporary equilibrium. The properties of non-negativity, symmetry, and linear homogeneity are satisfied at each observation by each model. Nonnegativity obtains immediately because prices, quasi-fixed inputs, output, and variable cost are positive. The non-negativity of $\ln c v(\cdot)$ is therefore not surprising because if $w, z$, and $q$ are positive so will $c v(\cdot)$. Symmetry and first-degree

Table 10.- Regularity diagnostics of the estimated translog variable cost function un temporary equilibrium ${ }^{\mathrm{a}}$

\begin{tabular}{|c|c|c|c|c|c|c|c|}
\hline \multirow{2}{*}{ № } & \multirow{2}{*}{ Property } & \multicolumn{6}{|c|}{ Models } \\
\hline & & 1 & 2 & 3 & 4 & 5 & 6 \\
\hline 1 & Symmetry in $w$ & 0 & 0 & 0 & 0 & 0 & 0 \\
\hline 2 & Non-negativity in $w$ & 0 & 0 & 0 & 0 & 0 & 0 \\
\hline 3 & Monotonicity in $w$ & 0 & 0 & 0 & 0 & 0 & 0 \\
\hline 4 & First-Degree Homogeneity in $w$ & 0 & 0 & 0 & 0 & 0 & 0 \\
\hline \multirow[t]{3}{*}{5} & Concavity in $w$ & & & & & & \\
\hline & Necessary condition & 0 & 27 & 33 & 20 & 32 & 2 \\
\hline & Sufficient condition & 0 & 28 & 33 & 20 & 33 & 5 \\
\hline 6 & Nonnegativity in $q$ & 0 & 0 & 0 & 0 & 0 & 0 \\
\hline 7 & Monotonicity in $q$ & 0 & 0 & 0 & 0 & 0 & 0 \\
\hline
\end{tabular}




\begin{tabular}{|c|l|c|c|c|c|c|c|}
\hline \multirow{2}{*}{ № } & \multicolumn{1}{|c|}{ Property } & 1 & 2 & 3 & 4 & 5 & 6 \\
\hline $\mathbf{8}$ & Symmetry in $z$ & 0 & 0 & 0 & 0 & 0 & 0 \\
\hline 9 & Nonnegativity in $z$ & 0 & 0 & 0 & 0 & 0 & 0 \\
\hline 10 & Nonincreasingness in $z$ & & & & & & \\
\hline & Capital input $(\boldsymbol{k})$ & 33 & 33 & 33 & 33 & 33 & 33 \\
\hline & Resource input $(\boldsymbol{n})$ & 15 & 29 & 29 & 14 & 33 & 0 \\
\hline 11 & Convexity in $z$ & 0 & 31 & 33 & 18 & 33 & 32 \\
\hline
\end{tabular}

a/ Entries in table denote number of observations at which the theoretical properties are violated.

b/ Properties 1, 2, 4, 6, and 9 do not conform part of the regularity diagnostics. Included in table for illustration purposes.

homogeneity are satisfied because they are imposed a priori on each model through parametric restrictions according to their mathematical interpretation shown in Table $2 .{ }^{34}$ Imposing these two properties a priori is consistent with common practice in applied classical econometrics. One typically treats symmetry and first-degree homogeneity as maintained hypotheses and use them as restrictions in estimation to guarantee a minimally consistent model economically. Guaranteed regularity, however, makes these three properties relatively uninteresting for the objectives of this study. Non-negativity, symmetry, and first-degree homogeneity, strictly speaking, do not form part of the regularity diagnostics. They are included in Table 10 for purposes of illustration.

Monotonicity in $w$ is also satisfied at each observation by each model. The translog variable cost function is positively monotonic in $w$ if each of the variable factor cost shares is positive. In practice, however, parameter estimates for $s_{i}$ can yield, in principle, a negative share. Notwithstanding this technical possibility, price monotonicity is typically satisfied empirically. Monotonicity in $q$ is also satisfied in every model, even though the spike in output registered for 1975 and the very large drop in output thereafter (see Figure 1), could have generated a violation in $q$-monotonicity.

Regularity diagnostics for the monotonicity of $\ln c v(\cdot)$ in $z$ is interesting. The translog specification of $c v(\cdot)$ for each model is negatively monotonic in $k$ and $n$ if the gradients of $\ln c v(\cdot)$ in $k$ and $n$ are negative. Not one model under temporary equilibrium $k$-monotonic. In fact, every model violates monotonicity in $k$ at every observation; that is thirty-three times! Models 1, 2, 3, 4, and 5 also fail to be monotonic in $n$ under temporary equilibrium. These models, however, are not as consistent in violating $n$ monotonicity as they are in violating $k$ monotoncity.

Consider now concavity. The translog variable cost function is $w$-concave if the own-price elasticities of demand are nonpositive or if the Hessian $w$-matrix is negative semidefinite. The sign condition of the elasticities is a necessary condition for concavity (NCC); ${ }^{35}$ the sign condition of the Hessian $w$-matrix is a sufficient condition (SCC). From Table 10 we seeviolations of NCC in all but the first model. Models 2, 3, 4, and 5 are subject to ill-behaved demand curves for $e, m$, and $l$ at the majority of observations. An incorrect relationship between $w$ and $q$ also holds for Model 6 for just a couple of observations. The number of observations at which SCC is violated is quite similar to the number of NCC violations. The sufficient condition is largely violated by all models except for the first. Model 1 is $w$-concave. From the data, it seems as if SCC is marginally harder to satisfy than NCC and that NCC-regularity does not necessarily imply regularity in SCC.

Finally, consider convexity. The translog variable cost function of each model is said to be convex if its Hessian matrix in $z$ is positive semidefinite. Except for Model 1, every model violates quasi-factor convexity for a large number of observations.

One observation in concluding this section involves the omnipresence of regularity violations in these types of models. These violations are a well-known fact in applied production analysis--though not always reported. Irregularity is an unfortunate and costly phenomenon. It hinders the attributes of relevant duality theorems and seriously limits the usefulness of flexible functional forms. Irregularity typically concentrates on the properties of concavity, quasi-fixed factor monotonicity, and convexity. There is no way to prevent these violations from happening in this study. These properties, unlike symmetry and first-degree homogeneity in $w$ represent curvature constraints and are characterized by algebraic inequalities. It is very difficult, if not impossible, to embed them in an econometric model consisting of a flexible functional form. Instead, the restrictions for monotonicity, concavity and convexity are applied as diagnostics, invoking them to check whether $\ln c v(\cdot)$ is consistent with theory. The frustration is compounded, moreover, when one takes into consideration that classical econometrics does not provide for an adequate way to cope with this phenomenon. The conclusion to this study addresses this issue once more as it sketches an agenda for future research.

A second and final observation in concluding this section involves the relative theoretical friendliness of Model 1. In effect, Model 1, of the six models, has the lowest number of theoretical violations. This observation is important because inasmuch as theoretical consistency varies across models, it should help us to find out whether different scale, technical change, and functional form assumptions exercise any statistically relevant effect upon rent as a measure of resource scarcity. If they do, then there would be something to say about the rent sensitivity to executive research decisions. 


\subsection{Rent Estimates}

The rent for $\boldsymbol{z}$ is obtained by solving for $p_{z}$ in equation (4). For $n, p_{n}=-\frac{\partial c v(\boldsymbol{w}, \mathbf{z}, q)}{\partial n}$ By solving for $\frac{\partial c v(\boldsymbol{w}, \mathbf{z}, q)}{\partial w_{i}}$, it is possible to
rewrite this previous equation more specifically as

$$
p_{n}=-S_{n} \frac{c v(\boldsymbol{w}, \mathbf{z}, q)}{n}
$$

where $s_{n}$ is the internal valuation of $n$. Rent estimates under temporary equilibrium were obtained using historical levels of $k$ and $\boldsymbol{n}$. Table 11 reports these estimates for each of the six models of Table 1.

In reviewing these numbers, notice that rent is negative for a large number of observations across models. These values result from the failure of the models to satisfy $n$ monotonicity at these observations (see Table 10). Each of the six models is $n$-monotonic if it satisfies the following inequality: $\nabla_{z} c v(\cdot) \leq 0_{m}$ (i.e., the non-increasingness in $z$ ). Property regularity here implies that $s_{n}$ is negative and, with the negative sign in equation (19), guarantees for a positive rent, since $c v(\cdot)$ and $n$ are positive.

Table 11.- Measures of natural resource scarcity rents under temporary equilibrium

\begin{tabular}{|c|c|c|c|c|c|c|}
\hline \multirow{2}{*}{ Year } & \multicolumn{6}{|c|}{ Models } \\
\hline & M1 & M2 & M3 & M4 & M5 & M6 \\
\hline 1953 & $\ldots$ & -1.00 & -1.00 & -1.00 & -1.00 & -1.00 \\
\hline 1954 & -1.00 & -0.70 & -0.60 & -0.79 & -2.14 & 1.40 \\
\hline 1955 & -0.57 & -0.60 & -0.42 & -0.82 & -2.96 & 0.71 \\
\hline 1956 & -0.43 & -0.39 & -0.33 & -0.46 & -3.14 & 1.34 \\
\hline 1957 & -0.28 & -0.36 & -0.27 & -0.36 & -3.66 & 1.59 \\
\hline 1958 & -0.27 & -0.20 & -0.15 & -0.19 & -3.63 & 2.26 \\
\hline 1959 & -0.18 & -0.21 & -0.07 & -0.33 & -3.84 & 1.71 \\
\hline 1960 & -0.26 & -0.13 & -0.13 & -0.12 & -3.48 & 1.54 \\
\hline 1961 & -0.21 & -0.11 & -0.13 & -0.09 & -3.37 & 1.38 \\
\hline 1962 & -0.18 & -0.10 & -0.11 & -0.10 & -3.33 & 1.20 \\
\hline 1963 & -0.14 & -0.08 & -0.10 & -0.08 & -3.26 & 1.14 \\
\hline 1964 & -0.10 & -0.11 & -0.10 & -0.11 & -3.49 & 1.02 \\
\hline 1965 & -0.02 & -0.11 & -0.05 & -0.19 & -3.59 & 0.75 \\
\hline 1966 & -0.06 & -0.13 & -0.11 & -0.10 & -3.60 & 0.80 \\
\hline 1967 & -0.09 & -0.10 & -0.16 & 0.06 & -3.33 & 1.02 \\
\hline 1968 & 0.00 & -0.17 & -0.18 & 0.05 & -4.02 & 1.06 \\
\hline 1969 & -0.01 & -0.17 & -0.19 & 0.06 & -3.98 & 1.00 \\
\hline 1970 & 0.07 & -0.23 & -0.23 & 0.09 & -4.61 & 1.08 \\
\hline 1971 & 0.20 & -0.33 & -0.25 & 0.10 & -5.59 & 1.17 \\
\hline 1972 & 0.29 & -0.38 & -0.27 & 0.14 & -6.45 & 1.43 \\
\hline 1973 & 0.25 & -0.44 & -0.32 & 0.16 & -6.99 & 1.37 \\
\hline 1974 & 0.28 & -0.53 & -0.40 & 0.21 & -8.42 & 1.54 \\
\hline 1975 & 0.22 & -0.13 & -0.26 & 0.81 & -9.14 & 4.21 \\
\hline 1976 & 0.37 & -0.61 & -0.47 & 0.48 & -10.92 & 2.76 \\
\hline 1977 & 0.43 & -0.70 & -0.54 & 0.50 & -12.06 & 2.78 \\
\hline 1978 & 0.52 & -0.63 & -0.54 & 0.81 & -13.67 & 4.15 \\
\hline 1979 & 0.58 & -0.79 & -0.63 & 0.88 & -15.31 & 4.41 \\
\hline 1980 & 0.71 & -0.70 & -0.57 & 1.03 & -17.03 & 5.25 \\
\hline 1981 & 0.67 & -0.44 & -0.46 & 1.43 & -18.25 & 7.21 \\
\hline 1982 & 0.64 & 0.33 & 0.01 & 2.19 & -17.50 & 11.32 \\
\hline 1983 & 0.88 & 0.46 & 0.30 & 2.42 & -18.82 & 13.66 \\
\hline 1984 & 0.53 & 0.65 & 0.32 & 2.44 & -16.79 & 13.69 \\
\hline 1985 & 0.33 & 0.68 & 0.27 & 2.20 & -14.45 & 12.35 \\
\hline
\end{tabular}


Are negative values for the rent meaningless? This question is worth addressing because it has been argued in the literature that a negative rent is not ruled out by theory and can be consistent with economic phenomena. Lasserre and Ouellette, for example, found negative values for their rent estimates and provided the following interpretation based on the economic environment of the Canadian asbestos industry between 1953 through 1985:

"In 1975, the valuation [i.e., the real implicit resource rental price] becomes negative, which is not surprising in a year marked by a six-month sector-wide strike over which production drops to about $60 \%$ of its previous level. Firms hold more reserves than necessary for production purposes: the marginal unit, if it were used, would have a negative marginal product. A similar situation prevails over the rest of the sample period, where demand drops to less than its initial 1953 level. However, since reserve additions practically become null over that period, reserves are allowed to diminish (to 62\% of their 1974 level in 1985), so that the valuation increases again and is almost reaching a positive value in 1985."36

Rents, accordingly, can become negative in the presence of prolonged sectoral labor conflicts, substantial decay in output over time, firms holding reserves as assets and not just for production purposes, or in the presence of a significant contraction in demand for the resource. That is, one should not be surprised to observe occurrences of a negative rent for a quasi-fixed input, particularly so with mineral reserves, if the firm, after some drastic change in its economic environment, finds itself holding more of the input that it can use at a positive marginal product. What is disturbing about this, however, is not so much whether it is possible to have a negative price, but rather the fact that it implies that violations of $\boldsymbol{n}$ monotonicity or, at a more general level, violations of negative monotonicity in $z$ can actually be necessary for the model to maintain relevance.

Lasserre and Ouellette acknowledged the absence of $n$ monotonicity for the observations of 1975 through 1985 in their econometric model, but considered it to be unsurprising. They argued, moreover, that a negative value for the rent is theoretically possible. Rent, however, is the difference between price and marginal cost; so, how can a negative value for such difference be sound? It is perfectly possible for the rate of change of the rent to be negative; so was discussed by Brown and Field (1979). Fisher (1979), for example, demonstrated formally that rent need not rise at the rate of interest or even monotonically in the presence of positive stock effects or in the absence of marginal extraction costs as reserves are depleted. But a negative rate of change does not mean that the rent is or can be negative. It is just too difficult to see the shadow price of the marginal unit of the resource in situ--that is, the effect on discounted future profits of removing (adding) the marginal unit from (to) the resource stock in the present--as a negative number.

Finally, notice also in Table 11 the drastic changes in the size of the rent estimates for

Figure 3 Canadian Asbestos industry Production, 1953-1985

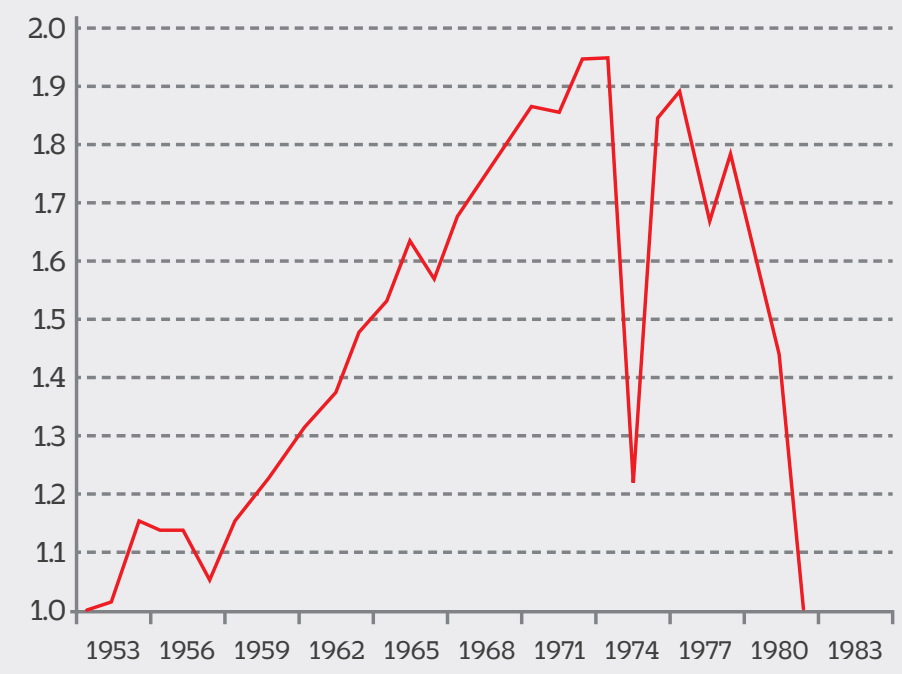

some of the models for the last four or five observations. Such a drastic change in the estimated value for rent seems peculiar, and appears to be linked to a very large spike in output. To see this, note that the computation of rent requires the estimates for variable cost and the internal valuation of reserves as well as the direct use of data on $n$ [see equation (19)]. Hence, any anomaly imbedded in variable cost, in the internal valuation of $n$ or in the time series for $n$ will affect the rent estimate. The size of the bias, of course, depends on what the anomaly is and where it resides. The blips in these estimates are largely driven by the substantial drop (spike) in output to which the asbestos industry was subject during the last five years of the sample period.

Figure 3 shows asbestos production between 1953 and 1985 in larger detail. The rate of change in output towards the end of the sample is striking. Between 1953 and 1974 output was subject to an increasing trend which peaked in 1974. The year of 1975 registered a drastic drop to be followed by a short-lived recovery and an almost monotonic decline in output. Details on the pattern of this trend are found in the excerpt of Lasserre and Ouellette quoted earlier. It can be shown that output exercised a 
substantial effect on the estimated series for variable cost and the internal valuation of $n$. The present empirical results of this study clearly and heavily depend on this spike, but, and very importantly, all estimates use the same data.

\subsection{Sensitivity Analysis}

Are the rent series or indexes reported in Table 11 statistically different across models? This is an important question because differences among indexes suggest that research decisions as a whole do play a relevant role in determining the value of rent econometrically. In order to answer this question a response surface model (RSM) is used with the series of Table 11. The objective of the RSM is to control for the characteristics of the models from which these indexes were derived as well as for inter-model differences. The RSM thus provides us with a simple yet comprehensive mechanism for assessing whether the research decisions that support the models have any statistical effect on their corresponding rent estimates. The RSM, accordingly, should include all of these series for an ideal scenario. But whether or not we end up working with all these indexes depends on selection criteria. If one uses completeness as a criterion, for example, all of these six indexes could be selected for response surface modeling. However, if theoretical consistency is taken into account, additionally, it would then be best to just work with those models that show the largest number of observations with positive rent estimates. In this context, let us work with models 1, 4 and 6. The RSM can be written in generic form as

$$
\mu=x \beta+u
$$

Where $\mu$ is the $(99 \times 1)$ dependent-variable vector composed of the selected rent series concatenated vertically according to the order in which they were identified above; $x$ is a $(99 \times 4)$ design matrix of regressors whose columns include an intercept, rent dummy variables, and a recursive time counter $\tau$; and $\boldsymbol{u} \sim N\left(0, \sigma^{2}\right)$. The RSM response surface is estimated by ordinary least squares. The empirical results are shown in Table 12.

The question of whether the rent series are different from each other is now answered in two steps. The first step consists of determining whether they share the same means. The intercept is the mean of the regressand when all regressors are zero. The means are said to be different from the mean of $\mu$ if the intercept and the intercept-altering dummy variable parameter estimates are statistically different from zero. If so, then there exist discrete shifts in the intercept parameter generating the data that are statistically relevant. In terms of equation (19), this entails

Table 12.- Response surface: statistical differences among rent estimates

\begin{tabular}{|l|c|c|c|}
\hline \multicolumn{1}{|c|}{ Parameter } & Estimate & Standard error & t-statistic \\
\hline Intercept & -2.7810 & 0.8129 & -3.4210 \\
\hline Model 1 dummy & -0.2914 & 0.9474 & -0.3074 \\
\hline Model 4 dummy & -0.0141 & 0.9479 & -0.0149 \\
\hline Time & 0.1961 & 0.0287 & 6.8250 \\
\hline
\end{tabular}

$$
E\left[p_{n t}\right]= \begin{cases}\left(\alpha+\beta_{M 1}\right)+\beta_{\tau} \tau_{t} & \text { for } t=1, \ldots, 33 \\ \left(\alpha+\beta_{M 4}\right)+\beta_{\tau} \tau_{t} & \text { for } t=34, \ldots, 66 \\ \alpha+\beta_{\tau} \tau_{t} & \text { for } t=67, \ldots, 99\end{cases}
$$

where the response parameters, save for $\beta_{\tau}$ represent the differences between the intercept values among the rent series or sample partitions of $\mu$. The relevant parameter estimates are not statistically different from zero at the 5 percent level of significance.

The second step consists of determining whether the parameter estimates of the dummy variables are different from each other statistically through a test involving a linear function among said estimates. To this effect, specifically, the null hypothesis $H_{0}: \beta_{M 1}-\beta_{M 4}=0$ is invoked. The null hypothesis is used to develop a restricted version of equation (19). Using the $F$ test statistic, we fail to reject the null hypothesis-see Table 15 . Here, $F_{q, t-k}$ is less than the right-tailed critical value for the $F$ distribution at the $5 \%$ level of significance. ${ }^{37}$

It is clear that there is not a statistically significant difference between the means of these indexes and the mean of $\mu$. The evidence also suggests that their means are not statistically different from each other. We can infer, accordingly, that the ex ante characteristics of the empirical specification of $c v(\cdot)$ do not to play an important role in modeling and measuring rent. Research decisions seem not to matter.

Can the link between the rent estimate and a particular characteristic of the empirical specification of $c v(\cdot)$, however, be isolated in order to evaluate whether said characteristic makes a difference? Although Table 12 and Table 13 provide information from which it is possible to infer if research decisions make a difference, they cannot provide information 

Table 13.- F tests involving linear functions of the dummy
variables of equation (20)

\begin{tabular}{|c|c|c|c|c|}
\hline Test & $\begin{array}{c}\text { Null } \\
\text { hypothesis }\end{array}$ & $\begin{array}{c}\text { Restricted } \\
\text { model SSE }\end{array}$ & $\begin{array}{c}\text { Test } \\
\text { statistic }\end{array}$ & Outcome $^{\mathrm{a}}$ \\
\hline 1 & $H_{0}: \beta_{M 1}=\beta_{M 4}$ & 2833 & 0.0856 & F.T.R. $H_{0}$ \\
\hline
\end{tabular}

a/ F.T.R. $H_{0}$ stands for fail to reject the null hypothesis.

from which the sensitivity of the rent to the particular assumptions on functional form, scale, and technical change involved in the empirical specification of $c v(\cdot)$, or to theoretical consistency, can be evaluated. The specification of the RSM is simple and it just does not provide for such information. A more comprehensive specification is required.

To this effect, let the previous response surface become, for the $i$ th observation,

$$
p_{n t}=\alpha+\beta_{\tau} \tau+\delta_{t}^{M 1} \tau_{t} d_{z t}^{M 1}+\delta_{t}^{M 4} \tau_{t} d_{t t}^{M 4}+\delta_{\text {lin }} d_{t}^{l i n}+\delta_{\text {mon }} d_{t}^{\text {mon }}+\delta_{c o n} d_{t}^{c o n}+\delta_{s c a} d_{t}^{s c a}+\delta_{t e c} d_{t}^{t e c}+\delta_{f b t} d_{t}^{f b t}+u_{t}
$$

Here $\alpha, \beta_{\tau}, \delta_{\tau}^{M j}(j=1,4)$, and the $\delta$ s with the three-letter subscripts are parameters to be estimated; $\tau$ is time; and $d_{\tau}^{M j}$ is a dummy variable interactive in $\tau$. Regressor $d^{\text {lin }}$ is the dummy variable for the research decision on functional form. It is specified, for illustration purposes, as

$$
d_{t}^{\text {lin }}\left\{\begin{array}{l}
1 \text { if } t=1, \ldots, 33 \\
0 \quad \text { Otherwise }
\end{array}\right.
$$

where a value of 1 is assumed for the observations corresponding to Model 1 , and a value of zero for all those corresponding to the linear models. In this very same context, dummy variables $d^{\text {mon }}$ and $d^{\text {con }}$ account for $n$-monotonicity and $\boldsymbol{w}$-concavity violations, respectively. ${ }^{38}$ Dummy variable $d^{\text {sca }}$ accounts for the research decision on scale, where a unit value is assumed for those observations in $\mu$ which were derived from a homothetic and nonhomogeneous technology, and a null value is assumed for those observations which were derived from a non-homothetic and nonhomogeneous technology. Regressors $d^{\text {tec }}$ and $d^{\text {fbt }}$ are the dummy variables for the research decisions on the presence and form of technical change, respectively; where the value of 1 is registered for those observations in $\mu$ which were derived from a technology subject to technical change or factorbiased technical change, and the value of zero is assumed for those observations which were correspondingly derived from a technology without technical change or subject to Hicks-neutral technical change. Finally, as before, $u$ is the residual, assumed to be spherical for simplicity.

The RSM is now a new structure in which vector $\mu$ is of order $(99 \times 1) ; x$ becomes a $(99 \times 10)$-order regressor design matrix; $\beta$ is a $(10 \times 1)$-order response parameter vector, and the corresponding residual vector $u$ is of dimension $(99 \times 1)$. The regressor design matrix contains ten regressors, most of which are dummy variables. Two of these are interactive in $\tau$ in order to capture slope differences with respect to this regressor in particular. ${ }^{39}$ The remaining dummies are binary variables with values of 1 or zero that capture qualitative characteristics of the models corresponding to $\mu$. These latter dummy variables identify whether the ex ante and ex post characteristics of the three empirical specifications of the variable cost function have any effect on the derivation and estimation of the selected rent series.

Table 14 reports the parameter estimates corresponding to the revised specification for the RSM. Rent is said to be sensitive to each of the specification assumptions if these estimates are statistically different from zero at an arbitrarily chosen significance level. According to the estimates, $\mu$ is sensitive to whether the model is theoretically consistent, homothetic and homogeneous, and subject to technical change, as well as the form of technical change. The rent, however, appears to be insensitive to the functional form of the models. All these estimates, except that for $d^{\text {lin }}$, are statistically different from zero at the 5 percent level of significance.

It is difficult to identify the actual cause or causes of having the parameter estimate for $d^{\text {lin }}$ statistically not different from zero without further research. There are, however, two important issues implicit in the implementation and estimation of the RSM that could be responsible, at least in part, for the apparent lack of sensitivity of $\mu$ to functional form. The first issue involves the intrinsic nature of dummy variables and their use in applied econometrics. The second issue involves the use of a geometrically distributed lag specification to describe technology in Model 1.

The use of dummy variables in applied econometrics is an ad hoc method or device for modeling our ignorance. Using a dummy variable is warranted when one wishes to model the causality or relationship between any two variables but do not know how to do 
Table 14.- Response surface model estimates

\begin{tabular}{|l|c|c|c|}
\hline \multicolumn{1}{|c|}{ Variable } & Estimate & Standard error & $t$-statistic \\
\hline Intercept & -0.0156 & 1.0060 & -0.0155 \\
\hline Time & 0.1796 & 0.0597 & 3.0110 \\
\hline M1 time dummy & 0.2728 & 0.0911 & 2.9930 \\
\hline M4 time dummy & 0.2253 & 0.0902 & 2.4990 \\
\hline n-monotonicity dummy & -4.1830 & 0.6663 & -6.2770 \\
\hline -concavity dummy & -3.8050 & 0.9420 & -4.0390 \\
\hline Scale dummy & -3.1530 & 1.0400 & -3.0310 \\
\hline Technical change dummy & 10.4100 & 1.7410 & 5.9800 \\
\hline Factor-biased technical change dummy & -2.9230 & 1.0260 & -2.8490 \\
\hline Linearity dummy & -0.0187 & 1.7750 & -0.0105 \\
\hline
\end{tabular}

so in explicit form. We know, for example, that all models in Table 1, except for the first, are linear. How can we model this qualitative characteristic in order to evaluate statistically its link to $\mu$ ? We just do not know of any other way than to use a binary dummy variable in which a 1 is assigned for a particular state of the characteristic in question and $\mathrm{O}$ for another. A problem in using dummy variables simultaneously in the design matrix, however, is that they can dampen each other out. If one dummy variable dampens another, for example, it is not possible to disentangle the individual effect of the latter dummy. In our RSM the description of the presence of any possible and statistically significant link between $\mu$ and the functional form of the model, represented by $d^{\text {lin }}$, could have very well been offset by any other participating dummy.

The second problem that could be partially responsible for the apparent lack of sensitivity of $\mu$ to the functional form of the models resides in the structure of Model 1. Model 1 is based on the model of Lasserre and Ouellette. It was included in Table 1 as a variation of a theme. It is the only one of the SUR equation systems that is nonlinear and dynamic. The model, however, is flawed from a logical point of view: the implementation of the dynamics sets forth an equilibrium condition that is structurally inconsistent with its similar from the cost-minimization paradigm.

The dynamics of Model 1 emerge from the specification of the technological indexes $\tau_{i}(\cdot), \tau_{r}(\cdot)$, and $\ln \tau_{0}(\cdot)$, as geometrically declining distributed lags. These forms are then turned into functions involving a common constant adjustment parameter $\lambda$ through a Koyck transformation in order to keep them manageable for estimation. It can be shown algebraically that equilibrium boils down to having current and past values of variable cost and the variable factor cost shares equal. Equal shares or valuations over two or more periods, however, do not imply a cost-minimizing combination of inputs. It is possible to have the share or valuation of an input be the same in value over two periods without necessarily having the cost-minimizing level of said input. In cost minimization, equilibrium is obtained by solving for optimal factor demand, from which, indeed, one can derive the cost-minimizing share. In a temporary-equilibrium model, for example, the producer problem consists of solving for the cost-minimizing quasi-fixed factor level in order to adjust the demand for variable inputs to its optimal state. That is, input choice, not shares, are the decision variables that are more relevant in defining the steady state.

We can thus assert based on these empirical results that model characteristics not only seem to have made a difference as a whole in modeling and measuring rent but also individually. The rent estimates are sensitive to the assumptions on scale and technical change adopted a priori for each model, as well as to the presence of theory violations. And it is perfectly possible, through a differently specified RSM, to see statistical sensitivity to functional form. Therefore, the message is clear: research decisions do make a difference; and, as result, they set the stage for what at a first glance appears to be a phenomenon one would welcome, but that actually is an uncomfortable dilemma: richness in choice.

In Table 1 there are six different models from which to choose. This richness in choice, however, is ironic because as it was discussed in the introduction to this research, classical econometrics does not provide a rule for choosing one model over another. Model selection is itself a difficult problem for which no commonly agreed upon solution exists in the context of many compiling objectives. It would certainly help, however, if competing sets of research decisions provided empirical results that are at least consistent with each other. This can be reworded in terms of the six models with the following question: are the estimates of the rent series conforming $\mu$ robust? This is a question to which this research now turns.

\subsection{Informational Consistency of Rent}

One way to answer the question of whether the rent series of $\mu$ are robust is by finding out if these series are trend-consistent; that is, do they move in the same direction and convey the same information about resource scarcity? This question is answered by computing a series-based correlation matrix. The correlation matrix is here used to determine whether these series are correlated with each other as well as the direction of such association. The means of the series are 0.0993 for Model 1 ; 0.3433 for Model 4 and 3.3120 for Model 6. The corresponding correlation matrix is 


$\left[\begin{array}{lll}1.0000 & 0.8637 & 0.6321 \\ 0.8367 & 1.0000 & 0.9402 \\ 0.6321 & 0.9402 & 1.0000\end{array}\right]$

There is a considerable amount of positive correlation of the means across these the models, indicating that these series largely move together in the same direction.

The three interactive dummy variables in $\tau$ of the second specification of the RSM, support this assertion and allows us, in addition, to determine the direction of change displayed by the rent series. The objective of including interactive time dummy variables for two of the three series in $x$, technically, is to control for slope differences in $\tau$ among each of the series. This implies algebraically

$$
E\left[p_{n t}\right]= \begin{cases}\alpha+\tau_{t}\left(\beta_{t}+\delta_{\tau}^{M 1}\right)+\delta_{\text {mon }} d_{t}^{\text {mon }}+, \ldots,+\delta_{\text {lin }} d_{t}^{\text {lin }} & \text { if } t=1, \ldots, 33 \\ \alpha+\tau_{t}\left(\beta_{t}+\delta_{\tau}^{M 4}\right)+\delta_{\text {mon }} d_{t}^{\text {mon }}+, \ldots,+\delta_{\text {lin }} d_{t}^{\text {lin }} & \text { if } t=34, \ldots, 66 \\ \alpha+\tau_{t} \beta_{t}+\delta_{\text {mon }} d_{t}^{\text {mon }}+, \ldots,+\delta_{\text {lin }} d_{t}^{\text {lin }} & \text { if } t=67, \ldots, 99 .\end{cases}
$$

Direction is established by the parameter estimates for $\tau$ and for the dummies interactive in $\tau$. A positive estimate suggests a rising trend while a negative estimate suggests a falling trend. Table 14 reported these estimates.

It is clear from the sign of the parameter estimates for $\tau$ in Table 12 and Table 14 that $\mu$ is subject to a positive trend. The estimates, moreover, are statistically different from zero at the 5 percent level of significance. They are also very similar and can be interpreted as robust in suggesting a rising trend for the rent over time in the Canadian asbestos industry. The parameter estimates for the two interactive dummy variables are also positive and statistically different from zero at the 5 percent level of significance. According to these estimates, there exist statistically relevant slope differences among most of the rent series. This suggests that not only is $\mu$ subject to a rising trend, but the series of which it is composed are also subject to a rising trend. The fact that $\mu$ is rising over time is in and of itself not a big finding; resources tend to grow scarcer as they are exploited over time--though for the case of the Canadian asbestos industry the positive trend of the rent appears to have been largely fueled by the contraction in output of the last ten sample years. What is important here is that each of these series is consistent with each other, for they indicate the same: rising scarcity rents.

\section{CONCLUSIONS}

The seemingly conflictive relationship between natural resource adequacy and economic activity is a longeval concern in which the measurement of resource scarcity has played a central role in assessing whether resources are growing scarce and represent a limit to growth. Evaluation of resource scarcity has involved the use of physical and economic measures. Of the economic measures of scarcity, rent is the preferred, particularly if there is interest on evaluating the adequacy of the resource in situ. Scarcity measurement based on rent, however, has not often been a choice in practice, in spite of its theoretical merits, for not being readily observed. Rent, notwithstanding, can be derived, by invoking Hotelling's lemma, from the variable cost function. The possibility to derive rent endogenously has curbed the paucity of data; but it has also brought forth important methodological issues intrinsic to measuring with more theory.

These issues largely involve the empirical specification and econometric estimation of the variable cost function. Consider the specification of the variable cost function for being of central importance to this study. To be sure, there are several ways in which one could specify the variable cost function. Choice, however, can prove to be more a methodological dilemma than a blessing. Do different specifications, for example, provide statistically different measures of scarcity based on rent? If they do, then choice gives us a problem of selection. A selection problem exacerbates if these measures are informationally inconsistent with each other, point at which we have, in addition, a problem of interpretation. Put differently, if functional form specification translates into statistically different and informationally inconsistent measures of scarcity based on rent, how does one select one model over another and interpret its results?

These questions are important for at least two reasons. First, they highlight the role of research decisions in the subjective search for the most relevant model under the classical approach to econometrics. Second, answers to these questions can provide insights for developing and using more comprehensive and thereby less confining methodologies for evaluating resource scarcity microeconometrically. Two objectives, to this effect, were established for this study. The first consisted of evaluating the sensitivity of rent as a measure of resource scarcity to the empirical specification of the variable cost function from which it is derived in order to assess whether alternative sets of assumptions on model characteristics translate into statistically different rent estimates. The second objective consisted of examining whether research decisions and theoretical consistency affect the information content of a measure of resource scarcity based on rent.

The main finding of this study is that research decisions on model characteristics translate into statistically different rent estimates across models but do not affect the information content of the rent as a measure of scarcity. In particular, rent 
appears to be sensitive to assumptions on scale and technical change; it is also sensitive to whether the models are theoretically consistent. Rent is statistically different across models but moves in the same direction thus suggesting increasing scarcity over the sample period.

The fact that research decisions translated into statistically different rent estimates across the six models, exposed how choice sets forth a problem of selection. In practice we generally do not entertain a single model specification for conducting research. Alternative specifications are typically considered for describing production technology and from which to choose. If we were to subject analysis and research conclusions to an original set of empirical results, or, better yet, if we could actually identify the specification of the model objectively, then there would be no purpose of which to speak for evaluating whether research decisions make a difference. But in fact we typically neither adhere to an original model specification and to its corresponding estimation outcome nor count with an objective rule for choosing one specification over another in classical econometrics. Many of us actually tend to specify the econometric model not in one but in several ways in order to subjectively search for the most convenient outcome.

In the absence of an appropriate rule for choosing one specification or model over another, it is nevertheless fortunate to have observed that competing sets of research decisions and model characteristics did not translate into rent estimates that are informationally inconsistent across models. The fact that research decisions translated into statistically different rent estimates across the six models also exposed, through the problem of selection, how it can set forth an interpretation dilemma. Choice fortunately did not set forth such a problem. Rent estimates were robust to research decisions, suggesting increasing scarcity in asbestos over the sample period in every model.

The findings of this study are meaningful inasmuch as they help us to identify complex theoretical and empirical issues underlying a microeconometric approach to measuring resource scarcity in order to set the stage for future research. Natural extensions to this study involve a more comprehensive microeconometric approach to measuring scarcity for which the methodological limitations upon which the empirical results rest have been accounted. Control of two of these limitations, in particular, proves to be critical for a more encompassing and theoretically richer focus: regularity violations and a comprehensive definition of temporary equilibrium upon factor fixity. ${ }^{40}$ Controlling for these limitations is intellectually and computationally demanding, doubtlessly, but it would certainly be necessary for obtaining more meaningful results.

Consider first theoretical consistency. Regularity violations comprise the main limitation of this study. The empirical specification of the variable cost function must satisfy the regularity properties which defines it in theory if restricted cost minimization theory is to serve as organizing principle. Theoretical consistency is fundamental because it guarantees a variable cost function that is well-behaved in prices, output, and quasi-fixed inputs--a necessary condition for the correct application of duality theorems in applied economic research. Unfortunately, not one of the models of this study turned out to be theoretically consistent. Regularity violations were ubiquitous and differed across models.

At the introduction to this study, it was asked if it makes a difference whether the empirical specification of the variable cost function is consistent with theory to the extent that said difference affects the information content of rent as a measure of scarcity. This question is important because if it does make a difference, then we should ask as well if future research should place specific emphasis in imposing theory consistency as prior information.

The empirical findings did show that rent is sensitive to whether the empirical specification of the variable cost function is theoretically consistent. The results thus represent further evidence on the necessity to impose theory consistency as prior information. Doing this, however, is a challenging enterprise. Alternative ways have been developed in the past using classical econometric methods. But these alternatives have proved to be for the most part overly restrictive and excessively demanding computationally when flexible functional forms are used to describe technology. Classical econometrics fails to provide for attractive ways to handle ubiquitous regularity violations when using flexible functional forms. Another approach to impose regularity as prior information involves Bayesian methods. These methods are becoming increasingly popular in economics because they provide for a formal framework in which we can incorporate regularity in the estimation of the variable cost function. Bayesian econometrics is extensively applicable, conceptually transparent, and objective. As Griffiths (1988) observed, moreover, it often offers a relatively more natural interpretation of statistical results. It may be the way to go in order to get rid of those wrong signs.

A more encompassing and theoretically richer model would also entail defining a temporary equilibrium with respect to all quasi-fixed inputs. Capital and reserves were treated as quasi-fixed inputs but for neither input was a temporary equilibrium defined. A short-term environment represents an important limitation if rent sensitivity to equilibrium is statistically relevant. To have defined a temporary equilibrium for these inputs would have allowed us to evaluate the sensitivity of rent to the state of equilibrium. But truth be told, this is not an easy task computationally. Long-run equilibrium would require solving simultaneously for the optimal employment levels of capital and reserves through their respective envelope equations. Solving for optimal demand in a system of nonlinear equations that represent first-order conditions for static equilibrium with numerical methods is easy neither by hand nor on the personal computer. This becomes more of a daunting task as one takes into consideration that rent to a quasi-fixed factor may not be available-i.e., reserves. Notwithstanding, a definition for temporary equilibrium on both factors would have certainly brought to surface important details which cannot be assessed otherwise. 
These limitations are certainly not new; they have been encountered before by many researchers and ways to curb their implications methodologically have been discussed in the economic literature. What obviously has not been addressed yet is how to account for these limitations in order to develop a richer microeconometric evaluation of the sensitivity of the rent to the empirical specification of the variable cost function. As our concern on whether natural resources are getting scarce and represent a limit to growth continues to stimulate research on resource adequacy, a better understanding of the nature of rent as a measure of resource scarcity is warranted.

1. This paper contains an excerpt of the doctoral research findings of this author, in memory of Professor Michael Hazilla--teacher, mentor, friend-- on the fifth anniversary of his passing.

2. See Pearce and Turner (1990), Fisher (1980), and Smith (1979) for an overview.

3. See, for example, Brown and Field (1979), Meadows, et al. (1972), and Barnett and Morse (1963).

4. See Escalante (1997), Lasserre and Oullette (1991), Halvorsen and Smith (1991), Hall and Hall (1984), Fisher (1979).

5. Duality theory ensures that $\operatorname{cv}(\cdot)$ is an equivalent representation of the technology, in the dual space, to the production function, such as $f(\cdot)$ See Diewart $(1982,1974,1971)$, and Shephard (1953).

6. The technology can be defined as follows in the primal space: the production possibilities set is $Q(\mathbf{x}) \equiv\left\{(q, \boldsymbol{x}) \in \mathrm{R}^{v+1}: f(\boldsymbol{x}) \geq q\right\}$, where $x$ is the $v$-vector of variable inputs; the factor requirement set is, then, $V(q) \equiv\left\{\boldsymbol{x} \in \mathrm{R}^{v}: f(\boldsymbol{x}) \geq q\right\}$, and the production isoquant is $I(q) \equiv\left\{\boldsymbol{x} \in \mathrm{R}^{v}: f(\boldsymbol{x})=q\right\}$, and represents the lower boundary of $V(q)$. See Varian (1992).

7. Variable cost is defined as $c v=\sum_{i=1}^{n} w_{i} x_{i}$.

8. See Hotelling (1931).

9. The transcendental logarithmic functional form is one of the most popular specifications in applied production analysis largely because of its flexibility and comprehensiveness to model technology empirically in the dual space. See Christensen, Jorgensen, and Lau (1973, 1972, 1971) for a review on the nature and attributes of the translog functional form and its general use in applied econometrics. See Diewart and Wales (1987), for a discussion on flexible functional forms and global curvature conditions. See Hall and Hall (1984), and Halvorsen and Smith (1991, 1984), for a specific application of these issues on natural resource scarcity measurement. See Escalante (1997), for a brief literature review on modeling production technology.

10. Disembodied change is considered over embodied change because it is simpler to account for empirically. One assumes disembodied technical change to be independent of the vintage structure of the factors of production. Embodied technical change, in contrast, cannot take place unless it is embodied in new capital--a fact that makes it harder to tract empirically.

11. Neutral technical change can be defined according to Harrod, Solow, and Leontief, in addition to Hicks. See Berndt and Wood (1982) for a review on Harrod-neutral, Solow-neutral and Leontief-neutral technical changes.

12. Model 1 is similar but not equal to the model of Lasserre and Ouellette. It is a variation thereof for two important reasons. The first, is:the discrepancy with their use of a technical bias component for output. Lasserre and Ouellette posed a translog specification that included a technical bias component for output, assumed to be driven by the same arguments of $\tau_{i}(\cdot)$ and $\tau_{r}(\cdot)$, and specified equivalently. Inclusion of this index, however, is redundant because any effect of technical change on $q$ is channeled neutrally and/or through the relationship between technical change and the factors of production. The second reason for why Model 1 differs from that of Lasserre and Ouellette involve variable factor aggregation.

13. The Koyck transformation and the adoption of a single adjustment constant, as opposed to several, comprise necessary steps to economize on the number of parameters and thus reduce stress on degrees of freedom in the estimation of each model of Table 1.

14. Lasserre and Ouellette (1991, p. 290)

15. A well-behaved function $g: R^{v} \rightarrow R$ is said to be homothetic if and only if it can be written as $g[h(\cdot)]$, where $h(\cdot)$ is a well-behaved first-degree homogeneous function in $x$ and $g(\cdot)$ is a monotonic function. See Footnote 17 for a definition of a homogeneous function. Function $g\left(x_{1}, \ldots, x_{v}\right)$ is said to be a positive monotonic transformation of $h: R^{v} \rightarrow R$, if $g(\cdot)$ is strictly increasing. If $g(\cdot) \rightarrow \infty$ as $h(\cdot) \rightarrow \infty$ and $g(0)=0$, then $g(\cdot)$ has the same properties of $h(\cdot)$. See Silberberg (1990) for a review of homothetic functions and functional transformations.

16. See Silberberg (1990) for a proof of this implication.

17. Function $h\left(x_{1}, \ldots, x_{v}\right)$ is said to be homogeneous of degree $r$ in $x$ if $h\left(k x_{1}, \ldots, k x_{v}\right) \equiv k k^{r} h(\cdot) \forall k>0 .(\cdot)$. (·). See Nicholson and Snyder (2012), for a review of homogeneous functions.

18. See Silberberg (1990) for a proof of this implication. See Hazilla and Kopp (1986) on testing of separable functional structures using temporary equilibrium models.

19. See Cobb and Douglas (1928)

20. Theoretical consistency continues to be a challenging problem in applied of production analysis. To be sure, approaches of how to deal with this issue have been introduced sporadically in the literature since the 1980s. Mathematical programming algorithms, for example, represent one of these approaches. Hazilla and Kopp (1986), used algorithms which permit explicit constrained optimization to impose these derivative consistency properties a priori. Explicit constrained optimization techniques freed them from having to embed the parametric restrictions directly in the objective function. Alternatively, Hazilla (1992) used numerical Bayesian methodology to overcome the limitations of classical econometrics in coping with the regularity problems repeatedly confronted when using the translog or other flexible functional forms. However, these and other approaches have tended to be overly restrictive or too difficult to implement computationally, and have yet to reach conventionality. In consequence, a substantial part of past and current research on applied production economics has, and continues to opt for theoretical consistency as diagnostics to verify whether these properties are met a posteriori.

21. See Shephard (1953) 
22. By definition the sum of the cost shares is 1 . This means that only $n-1$ are linearly independent. The linear dependency of $s_{i}$ implies that the sum of the disturbances across the system equations is zero at each observation; that is, the disturbance covariance matrix is singular. It is practically impossible to estimate an econometric system whose covariance matrix exhibits singularity. This problem, however, is overcome by removing $s_{i}$ from the system for indirect estimation. The solution does raise the concern of whether parameter estimates are sensitive to the exclusion of $s_{i}$. It would be a troubling feature of the estimation process, as Berndt (1991) observed, if estimates were sensitive to the choice of which share equation is deleted since it would permit to report only those results that best match expectations. Barten (1969), however showed that parameter estimates are invariant to the choice of which share equation is deleted if the system is estimated by maximum likelihood.

23. Convergence criterion is defined for the present models as having the absolute value of the change in the objective function being less than 1.E-09.

24. These equalities are, specifically, i $\operatorname{var}\left(u_{1 t}\right)=E\left[u_{1 t}\right]^{2}=\sigma_{1}^{2}=\sigma_{11}, \operatorname{var}\left(u_{2 t}\right)=E\left[u_{2 t}\right]^{2}=\sigma_{2}^{2}=\sigma_{22}, \ldots, \operatorname{var}\left(u_{m t}\right)=E\left[u_{m t}\right]^{2}=\sigma_{m}^{2}=\sigma_{m m^{\prime}}$ where var is the variance operator and $E$ is the expectations operator; $\operatorname{cov}\left(u_{i t} u_{j t}\right)=E\left[u_{i t} u_{j t}\right]=\sigma_{i j}, i, j=1, \ldots, m$ where $\operatorname{cov}$ is the covariance operator; and $\operatorname{cov}\left(u_{i t} u_{j t}\right)=E\left[u_{i t} u_{j l}\right]=0, t \neq l$ To be sure, there are several and more general ways of specifying the stochastic framework for these systems (e.g., those involving first-order autocorrelation), but the assumption of a joint asymptotically normal distribution for these errors has been typical for such model. See Berndt (1991) for further discussion.

25. See Judge, Hill, Griffiths, Lütkepohl, and Lee (1988) for a formal review on nonlinear ML estimation.

26. See Judge, Hill, Griffiths, Lütkepohl, and Lee (1985) for a review of the DFPMIN algorithm.

27. The value of $\lambda$ is restricted to the $[0,1]$ interval. An increment of 0.05 is assigned to the marginal value of $\lambda$, starting at 0.05 and ending at 0.95 . Note that for every value of $\lambda$ the system can be treated in linear form. Thus, at each value the parameter of the system (save for $\lambda$, of course), are estimated with ML and SSE is computed. Once the value of $\lambda$ that yields the smallest SSE is found (say $\lambda$ ), one identifies its neighborhood as $[\hat{\lambda}-0.05, \hat{\lambda}+0.05]$, and repeat the search for further accuracy. At this time, the increment of the marginal value for $\lambda$ has to be smaller; a value of 0.01 is chosen

28. Nonlinear SUR estimation requires iterating on the covariance matrix. The covariance matrix is initialized as an identity matrix to then iterate on it three times in the present instance.

29. To this end, two convergence criteria are chosen: an absolute value for the change in the objective function which is less than 1 .E-05 and Belsley's criterion, also less than 1.E-05. The objective function in nonlinear SUR estimation consists of minimizing the weighted SSE across iterations. The objective in nonlinear ML consists for this case of the minimization of the determinant of the cross-product moment matrix (objective function) across iterations. See Belsley (1980) for a discussion of Belsley's criterion.

30. The GAUSS computer programs are available upon request.

31.Data normalized to 1 in 1953 for purposes of estimation.

32. See Berndt (1991) for this and alternative specifications of the likelihood ratio.

33. Failure to reject this hypothesis formalizes the information portrayed by the ratios of parameter estimates to asymptotic standard errors corresponding to the parameters $\beta_{e q}, \beta_{m q} \beta_{k q}$ and $\beta_{s q}$ in models 1, 2, 3, 4, and 6 . These parameters incorporate the assumption of a non-homothetic technology into the models. Notwithstanding, at a 5 percent level of significance, $\beta_{\text {eq }}$ is statistically not different from zero

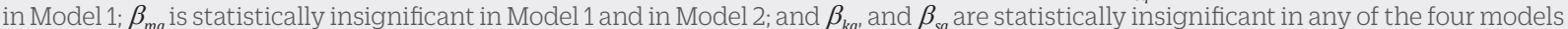
in which they are contemplated. This suggests, albeit informally, that homotheticity might be consistent with the data. Another example involves the ratios of the substitution parameters $\beta_{e e^{\prime}} \beta_{m m^{\prime}}$ and $\beta_{e m}$ These ratios suggest that a hypothesis for a non-unitary elasticity of substitution might also be inconsistent with the data. Similar observations can be derived regarding hypothesis on technical change.

34. Obviously these properties serve as useful benchmarks in developing the GAUSS computer programs used in this research. Failure to satisfy these properties then must result from an algebraic and/or a programming mistake.

35. Own-price elasticity estimates are available upon request.

36. Lasserre and Ouellette (1991, p. 306)

37. Notice that the outcome on $\mathrm{H}_{0}$ can largely be anticipated by the difference between $\mathrm{SSE}_{\mathrm{R}}$ and $\mathrm{SSE}_{\mathrm{U}}$, and between the corresponding $\mathrm{R}^{2 \text { 's }}$ (not shown). The null hypothesis is generally rejected if $\mathrm{SSE}_{\mathrm{R}}$ is significantly larger than $\mathrm{SSE}_{\mathrm{U}}$; and one fails to reject $\mathrm{H}_{0}$ if $\mathrm{SSE}_{\mathrm{R}}$ is insignificantly larger than $\mathrm{SSE}_{\mathrm{U}}$. Whether the difference between the sum of squared errors is significant or merely symbolic can and is generally determined by $\mathrm{F}_{\mathrm{q}, \mathrm{t}-\mathrm{k}}$

38. A value of 1 implies a rent value generated with either or both properties violated, whereas a value of zero implies one generated with a model consistent in either or both properties.

39. The role of $\tau$ and its interactive dummy variables in the RSM are addressed in the next section.

40. Other limitations that would narrow the interpretation of the empirical results of this study involve the weak dynamic structure assumed for the adjustment mechanism for technical change in Model 1; not having accounted for uncertainty in measuring resource scarcity: reporting rent estimates without standard error; and not having used other flexible functional forms in addition to the translog. 


\section{REFERENCES}

Allen, R. G. D. (1938). Mathematical Analysis for Economists. London: Macmillan \& Co.

Atkinson, S. \& Halvorsen, R. (1976). Interfuel substitution in steam electric power generation. Journal of Political Economy, 84(5), 959-978.

Barnett, H. J. (1979). Scarcity and Growth Revisited. In V. K. Smith (Ed.), Scarcity and Growth Reconsidered (pp. 163-217). Baltimore, MD: The Johns Hopkins University Press.

Barnett, H. J. \& Morse, C. (1963). Scarcity and Growth: The Economics of Natural Resource Availability. Baltimore, MD: The Johns Hopkins University Press.

Barnett, H. J., van Muiswinkel, G. M. \& Shechter, M. (1982). Are minerals costing more? Resource Management Optimization 2 121-148.

Barten, A. P. (1969). Maximum likelihood estimation of a complete system of demand equations. European Economic Review 1 , $7-73$.

Baumol, W. J., Batey Blackman, S. A., \& Wolff, E. N. (1989). Productivity and American Leadership: The Long View. Cambridge, MA MIT Press.

Belsley, D. (1980). On the Efficient Computation of the Nonlinear Full-Information Maximum Likelihood Estimator (Technical Report 5, Vol. 2). Cambridge, MA: Center for Computational Research in Economics and Management Science.

Berndt, E. R. (1991). The Practice of Econometrics: Classic and Contemporary. Reading, PA: Addison-Wesley Publishing

Berndt, E. R., \& Fuss, M. A. (1986). Productivity measurements with adjustments for variations in capacity utilization and other forms of temporary equilibrium. Journal of Econometrics, 7-29.

Berndt, E. R., \& Khaled, M. S. (1979). Parametric productivity measurement and choice among flexible functional forms. Journal of Political Economy, 87, 1220-1245.

Berndt, E. R., \& Wood, D. O. (1982). The specification and measurement of technical change in U.S. manufacturing. In J. R. Moroney (Ed.), Advances in the Economics of Energy and Resources: Vol. 4 (pp. 199-221). Greenwich, CT: JAI Press.

Binswanger, H. (1974). A cost function approach to the measurement of factor demand and elasticities of substitution. American Journal of Agricultural Economics, 56, 377-386.

Brobst, D. A. (1979). Fundamental concepts for the analysis of resource availability. In V. K. Smith (Ed.), Scarcity and Growth Reconsidered (pp. 106-142). Baltimore, MD: The Johns Hopkins University Press.

Brown, G. M., \& Field, B. (1979). The adequacy of measures for signaling the scarcity of natural resources. In V. K. Smith (Ed.), Scarcity and Growth Reconsidered (pp. 218-247). Baltimore, MD: The Johns Hopkins University Press.

Brown, R. S., \& Christensen, L. R. (1981). Estimating elasticities of substitution in a model of partial static equilibrium: An application to U.S. agriculture, 1947 to 1974. In E. R. Berndt, \& B. C. Field (Eds.), Measuring and Modeling Natural Resources. Cambridge, MA: MIT Press.

Chambers, R. G. (1988). Applied Production Analysis: A Dual Approach. UK: Cambridge University Press.

Chiang, A. C. (1992). Elements of Dynamic Optimization. New York, NY: McGraw-Hill

Chiang, A. C. (1984). Fundamental Methods of Mathematical Economics (3rd ed.). New York, NY: McGraw-Hill

Christensen, L., Jorgenson, D., \& Lau, L. (1971). Conjugate duality and the transcendental logarithmic production function. Econometrica, 39, 255-256.

Christensen, L., Jorgenson, D., \& Lau, L. (1972). Conjugate Duality and the Transcendental Logarithmic Production Frontiers (Discussion Paper 238). Cambridge, MA: Harvard Institute of Economic Research.

Christensen, L., Jorgenson, D., \& Lau, L. (1973). Transcendental logarithmic production frontiers. Review of Economics and Statistics, 55, 367-383.

Cobb, C. W., \& Douglas, P. H. (1928). A theory of production. American Economic Review [March supplement], 139-165.

Daly, H. E. (1979). Entropy, growth, and the political economy of scarcity. In V. K. Smith (Ed.), Scarcity and Growth Reconsidered (pp. 67-94). Baltimore, MD: The Johns Hopkins University Press.

Devarajan, S. and Fisher, A. C. (1982). Exploration and scarcity. Journal of Political Economy, 1279-1290. 
Diewert, W. E. (1971). An application of the Shephard Duality Theorem: A generalized Leontief Production Function. Journal of Political Economy, 79, 481-507.

Diewert, W. E. (1974). Applications of Duality Theory. In M. D. Intriligator, \& D. A. Kendrick (Eds.), Frontiers in Quantitative Economics: Vol. 2 (pp. 106-171). The Netherlands: North-Holland Publishing.

Diewert, W. E. (1982). Duality approaches to microeconomic theory. In K. J. Arrow, \& M. D. Intriligator (Eds.), Handbook of Mathematical Economics: Vol. 2 (pp. 535-599). The Netherlands: North-Holland Publishing.

Diewert, W. E., \& Wales, T. J. (1987). Flexible functional forms and global curvature conditions. Econometrica, 55, 43-68.

Dwivedi, T. K., \& Srivastava, K. (1978). Optimality of least squares in the seemingly unrelated regressions model. Journal of Econometrics, 7,391-395.

Escalante, A. A. (1997). Microeconometric evaluation of natural resource scarcity under Restricted Cost Minimization Theory: Sensitivity, theoretical consistency, and structural dynamics. (Ph.D. Dissertation, American University).

Fisher, A. C. (1979). Measures of natural resource scarcity. In V. K. Smith (Ed.), Scarcity and Growth Reconsidered (pp. 249-275). Baltimore, MD: The Johns Hopkins University Press.

Fisher, A. C. (1980). Resource and Environmental Economics. UK: Cambridge University Press.

Fuss, M. A. (1977). The demand for energy in Canadian manufacturing: An example of the estimation of production structures with many inputs. Journal of Econometrics, 5, 89-116.

Gallant, A. R. (1981). On the bias in flexible functional forms and an essentially unbiased form: The Fourier Flexible Form. Journal of Econometrics, 15, 211-245.

Gerald, C. F., \& Wheatley, P. O. (1992). Applied Numerical Analysis (4th ed.). Reading, PA: Addison-Wesley Publishing.

Greene, W. H. (2012). Econometric Analysis (7th ed.). Boston, MA: Pearson Education Inc.

Griffiths, W. E. (1988). Bayesian econometrics and how to get rid of those wrong signs. Review of Marketing and Agricultural Economics, 56, 36-56.

Hall, D. C., \& J. V. Hall. (1984). Concepts and measures of natural resource scarcity with a summary of recent trends. Journal of Environmental Economics and Management, 11, 363-379.

Halvorsen, R., \& Smith, T. R. (1984). On measuring natural resource scarcity. Journal of Political Economy, 92, 954-964.

Halvorsen, R., \& Smith, T. R. (1991). A test of the theory of exhaustible resources. The Quarterly Journal of Economics, 106, 123-140.

Hazilla, M. (1988). Testing for separable functional structure using temporal equilibrium models: Imposing Partial Allen Elasticity of Substitution Equivalence in a variable cost function model subject to economic consistency conditions. Lecture conducted at Washington State University.

Hazilla, M. (1991). Econometric analysis of market structure: Statistical evaluation of price-taking behavior and market power. Advances in Econometrics, 9, 3-59

Hazilla, M. (1992). The Bayesian Econometrics of temporary equilibrium models under regularity. Department of Economics, American University, Washington, D.C.

Hazilla, M., \& Kopp, R. J. (1986). Testing for separable functional structure using temporary equilibrium models. Journal of Econometrics, 33, 119-142.

Heady, E. O., \& Dillon, J. L. (1961). Agricultural Production Functions. Ames, IA: Iowa State University Press.

Herfindahl, O. C. (1961). Three Studies in Mineral Economics. Washington, D.C.: Resources for the Future.

Hicks, J. R. (1963). The Theory of Wages (3rd ed.). London: Macmillan \& Co.

Hotelling, H. (1931). The economics of exhaustible resources. Journal of Political Economy, 39, 137-175.

Johnson, M., \& Bell, F. W. (1978). Resources and scarcity: Are there limits to growth? Department of Economics, George Mason University, Washington, D.C.

Johnston, J. (1984). Econometric Methods (3rd ed.). New York, NY: McGraw-Hill

Jorgenson, D. W. (1986). Econometric Methods for Modeling Producer Behavior. In Z. Griliches, \& M. D. Intriligator (Eds.), Handbook of Econometrics: Vol. 3 (pp. 1842-1915). New York, NY: Elsevier Science Publishers BV.

Judge, G. G., Carter Hill, R. C., Griffiths, W. E., Lutkepohl, H., \& Lee, T.C. (1985). The Theory and Practice of Econometrics (2nd ed.). New York, NY: John Wiley \& Sons. 
Judge, G. G., Carter Hill, R. C., Griffiths, W. E., Lutkepohl, H., \& Lee, T.C. (1988). Introduction to the Theory and Practice of Econometrics (2nd ed.). New York, NY: John Wiley \& Sons.

Kamien, M. I., \& Schwartz, N. L. (1982). Toward reformulating the role of natural resources in economic models. In V. K. Smith, \& J. V. Krutilla (Eds.), Explorations in Natural Resource Economics (pp. 3-43). Baltimore, MD: The Johns Hopkins University Press, 1982.

Kmenta, J., \& Gilbert, R. (1968). Small sample properties of alternative estimators of seemingly unrelated regressions. Journal of the American Statistical Association, 63, 1180-1200.

Koyck, M. (1953). Distributed Lags and Investments Analysis. New York, NY: North Holland Publishing.

Lassere, P., \& Oullette, P. (1991). The measurement of productivity and scarcity rents: The case of asbestos in Canada. Journal of Econometrics, 48(3), 287 - 312.

McFadden, D. (1978). Cost, revenue and profit functions. In M. Fuss, \& D. McFadden (Eds.), Production Economics: A Dual Approach to Theory and Application: Vol. 2 (pp. 3-101). The Netherlands: North-Holland Publishing.

McFadden, D. (1966, March). Cost, revenue and profit functions: A cursory review (IBER Working Paper No. 86). Berkeley, CA: University of California

McKelvey, V. E. (1972). Mineral resource estimates and public policy. American Scientist, 60, 32-40.

Meadows, D. H., Meadows, D. L., Randers, J., \& Behrens, W. W. (1972). The Limits to Growth. New York, NY: University Books.

Morrison, C. J. (1988). Quasi-fixed inputs in US and Japanese manufacturing: A Generalized Leontief Restricted Cost Function approach. Review of Economics and Statistics, 70, 275-287.

Nadiri, M. I. (1982). Producer's theory. In K. J. Arrow, \& M. D. Intriligator (Eds.), Handbook of Mathematical Economics (pp. 431-490). The Netherlands: North-Holland Publishing.

Newman P. (1987). Duality. In J. Eatwell, M. Milgate, \& P. Newman (Eds.), The New Palgrave: Vol. 1 (pp. 924-934). London: The Macmillan Press, Ltd.

Nicholson, W., \& Snyder, C. (2012). Microeconomic Theory: Basic Principles and Extensions (11th ed.). Chicago, IL: South Western/ Cengage Learning.

Norgaard, R. B. (1990). Economic indicators of resource scarcity: A critical essay. Journal of Environmental Economics and Management, 19, 19-25.

Nordhaus, W. D. (1974) Resources as a constraint on growth. American Economic Review, 22-26.

Nordhaus, W. D. (1973). World dynamics: Measurement without data. Economic Journal, 83, 1156-1183.

Ohta, M. (1974). A note on the duality between production and cost functions: Rate of returns to scale and rate of technical progress. Economics Studies Quarterly, 25, 63-65.

Pearce, D. W., \& Turner, R. K. (1990). Economics of Natural Resources and the Environment. Baltimore, MD: The Johns Hopkins University Press.

Peterson, F. M., \& Fisher, A. C. (1977). The exploitation of extractive resources: A survey. Economic Journal, 87, 681-721.

Pindyck, R. S. (1978). The optimal exploration and production of nonrenewable resources. Journal of Political Economy, 86, 841861.

Pindyck, R. S., \& Rubinfeld, D. L. (1998). Econometric Models and Economic Forecasts (4th ed.). New York, NY: McGraw-Hill.

Potter, N., \& Christy, F. T. (1998). Trends in Natural Resource Commodities: Statistics of Prices, Output, Consumption, Foreign Trade and Employment in the United States, 1870-1957. Baltimore, MD: The Johns Hopkins University Press.

Press, W. H., Flanney, B. P., Tevkolsky, S. A., \& Vetterling, W. T. (1990). Numerical Recipies: The Art of Scientific Computing. New York, NY: Cambridge University Press.

Robinson, C. (1975). The Depletion of Energy Resources. In D. W. Pearce and J. Rose (Eds.), The Economics of Natural Resource Depletion (pp. 21-55). New York, NY: John Wiley \& Sons.

Robinson, T. J. C. (1989). Economic Theories of Exhaustible Resources. London: Routledge.

Samuelson, P. A. (1948). Foundations of Economic Analysis. Cambridge, MA: Harvard University Press.

Schumpeter, J. A. (1953). History of Economic Analysis. Cambridge, MA: Harvard University Press.

Shephard, R. W. (1953). Cost and Production Functions. Princeton, NJ: Princeton University Press.

Silberberg, E. (1990). The Structure of Economics: A Mathematical Analysis (2nd ed.). New York, NY: McGraw-Hill 
Slade, M. (1982). Trends in natural resource commodity prices: An analysis of the time domain. Journal of Environmental Economics and Management, 9, 122-137.

Smith, V. K. (1979). Natural resource scarcity: A statistical analysis. Review of Economics and Statistics, 61, 423-427.

Smith, V. K., \& Krutilla, J. V. (1982). Toward reformulating the role of natural resources in economic models. In V. K. Smith and J. V. Krutilla (Eds.), Explorations in Natural Resource Economics (pp. 3-43). Baltimore, MD: The Johns Hopkins University Press.

Smith, V. K., \& Krutilla, J. V. (1979). The economics of natural resource scarcity: An interpretative introduction. In V. K. Smith (Ed.), Scarcity and Growth Reconsidered (pp. 1-28). Baltimore, MD: The Johns Hopkins University Press.

Solow, R. M. (1957). Technical change and the production function. Review of Economics and Statistics, 39, 312-320.

Solow, R. M. (1974). Richard T. Ely lecture: The economics of resources or the resources of economics. American Economic Review, $64,1-14$

Stiglitz, J. E. (1976). Monopoly and the rate of extraction of exhaustible resources. The American Economic Review, 66, 655-661.

Stiglitz, J. E. (1979). A neoclassical analysis of the economics of natural resources. In V. K. Smith (Ed.), Scarcity and Growth Reconsidered (pp. 36-66). Baltimore, MD: Johns Hopkins University Press.

Varian, H. R. (1992). Microeconomic Analysis (3rd ed.). New York, NY: W. W. Norton \& Co.

Uzawa, H. (1964). Duality principles in the Theory of Cost and Production. International Economic Review, 5, 216-220.

Zellner, A. (1962). An efficient method of estimating seemingly unrelated regressions and tests for aggregation bias. Journal of the American Statistical Association, 57, 348-368.

Zimmerman, M. B. (1977). Modeling depletion in a mineral industry: The case of coal. Bell Journal of Economics, 8, 41-65. 